Université de Montréal

\title{
The effect of background music on episodic memory
}

par Elise Cournoyer Lemaire

Département de psychologie

Faculté des Arts et des Sciences

Mémoire présenté

en vue de l'obtention du grade de maîtrise

en psychologie

juillet, 2017

(C) Elise Cournoyer Lemaire, 2017 


\section{Résumé}

La majorité des étudiants universitaires rapportent étudier en écoutant de la musique car celle-ci améliorerait leurs performances cognitives, incluant la mémorisation de nouvelles informations. Cependant, les résultats de la littérature quant à l'effet de la musique de fond sur la mémoire épisodique (i.e. la mémoire à long-terme pour des événements spatiotemporels) sont hétérogènes. En effet, des effets bénéfiques, parfois nuisibles et nuls sont observés. Cette hétérogénéité des résultats pourrait s'expliquer par des différences méthodologiques et individuelles à travers les études. En effet, les caractéristiques émotionnelles des musiques varient. Notamment, les musiques diffèrent de par leur niveau d'activation, soit de caractère relaxant ou stimulant. De plus, les différences individuelles telles que le quotient intellectuel ont été peu considérées dans les études antérieures.

L'objectif central de cette étude est donc d'explorer l'effet de la musique de fond stimulante et relaxante sur la mémoire épisodique en considérant les variations du quotient intellectuel. Pour cela, trois groupes de participants appariés selon le sexe, l'âge, la scolarité et l'expertise musicale ont mémorisé trois listes de mots en présence de musique stimulante ou relaxante, ou de bruit. Les résultats indiquent que la musique stimulante, comparativement à la musique relaxante et au bruit, a marginalement facilité la mémorisation de la troisième liste, et ce, seulement en considérant le quotient intellectuel. Ces résultats suggèrent que la mémoire épisodique pourrait bénéficier de la présence de musique de fond stimulante mais dans le cas d'une écoute prolongée et en considérant le quotient intellectuel des auditeurs.

Mots-clés : Musique de fond, mémoire épisodique, émotions musicales, niveau d'activation, quotient intellectuel 


\section{Abstract}

Most university students report studying while listening to background music because it would help them to improve their cognitive performances, including the memorization of new information. However, results from the literature regarding the effect of background music on episodic memory (i.e. the long-term memory for spatiotemporal events) are heterogeneous. Indeed, beneficial effects, and sometimes impairing and null effects are observed. The heterogeneity in these results could be explained by methodological and individual differences across studies. Indeed, the emotional characteristics of the musical selection vary. Namely, the musical excerpts vary in their arousal levels, being either stimulating or relaxing. Moreover, individual differences such as intellectual quotient were rarely considered in previous research.

Thus, the central aim of this study is to explore the effect of stimulating and relaxing background music on episodic memory while considering the variability in intellectual quotient. To do so, three groups of participants matched on sex, age, schooling years and musical expertise memorized three word lists in the presence of stimulating or relaxing background music, or noise. Results indicate that the stimulating background music, compared to the relaxing background music and noise, marginally facilitated the memorization of the third list, only when the intellectual quotient was considered. These results suggest that episodic memory could benefit from the presence of stimulating background music, but in the context of a prolonged music listening and when considering the listeners' intellectual quotient.

Keywords : Background music, episodic memory, musical emotions, arousal level, intellectual quotient 


\section{Table of contents}

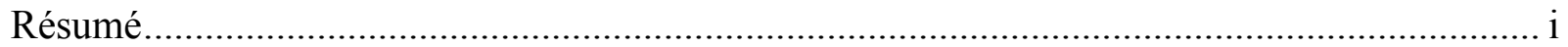

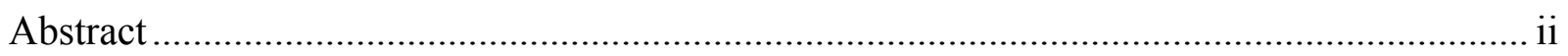

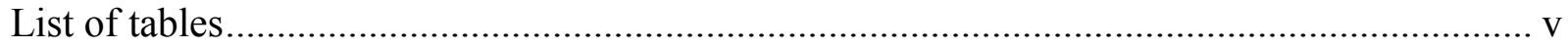

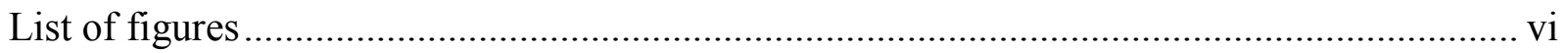

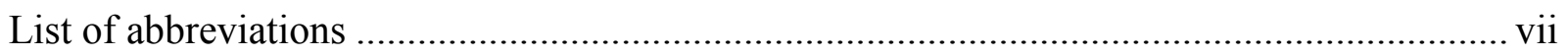

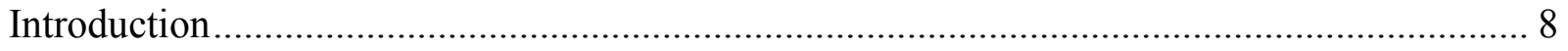

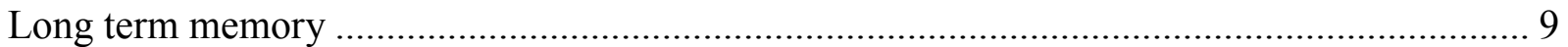

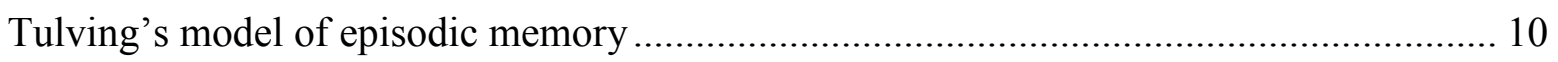

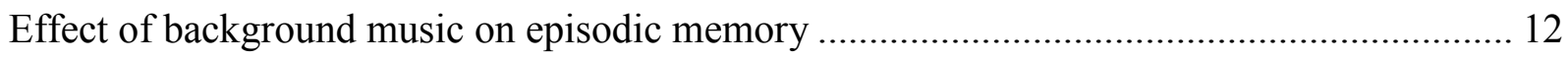

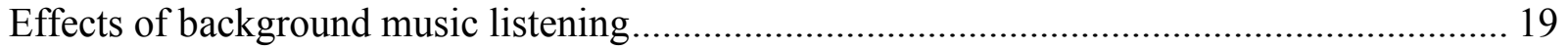

Emotional regulation and musical emotions.............................................................. 19

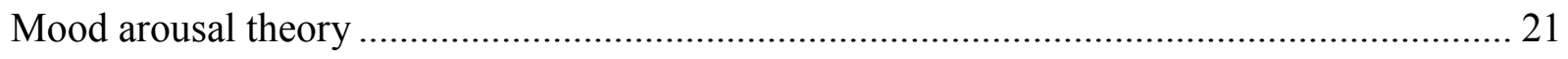

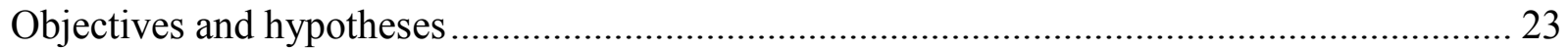

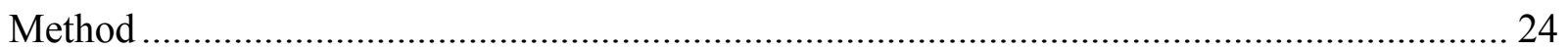

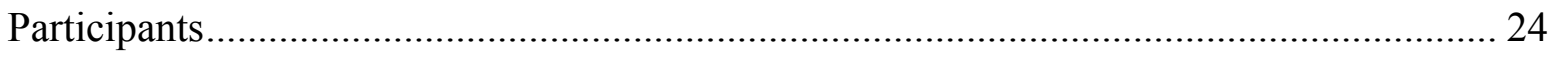

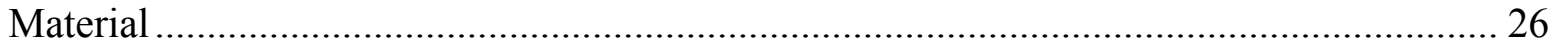

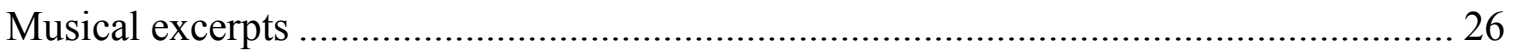

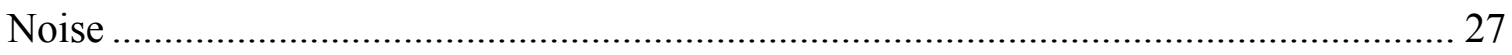

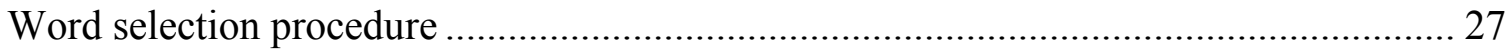

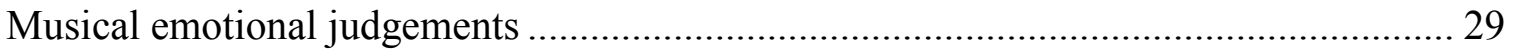

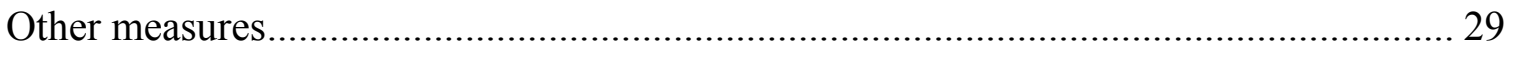

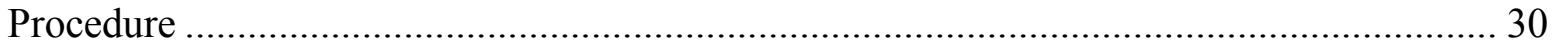

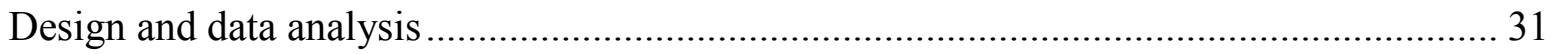

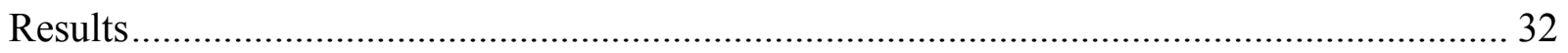

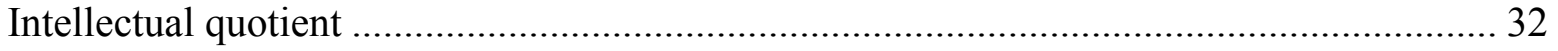

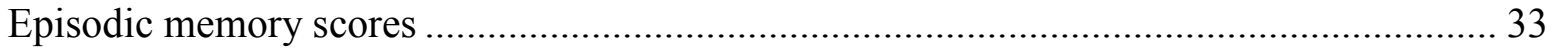

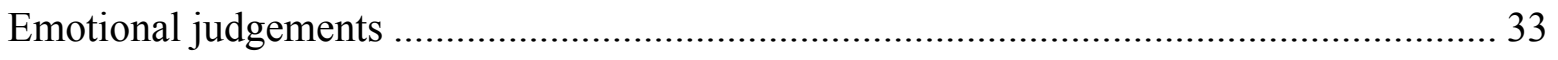

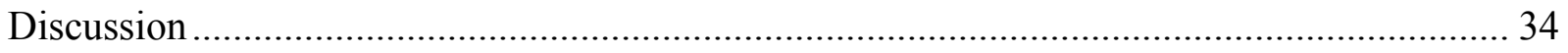

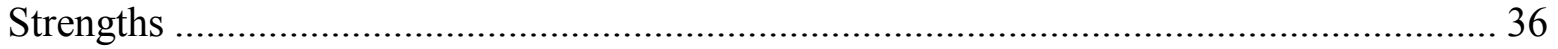


Limitations and future research

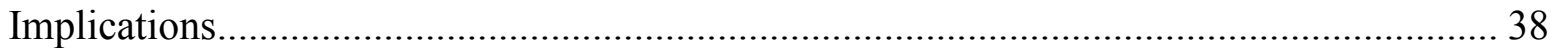

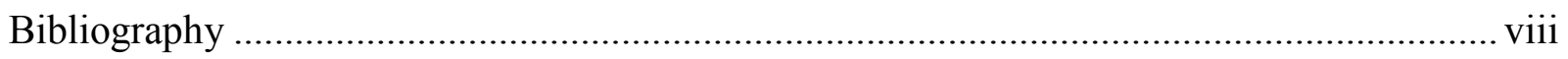

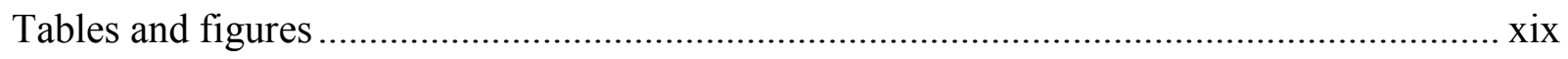

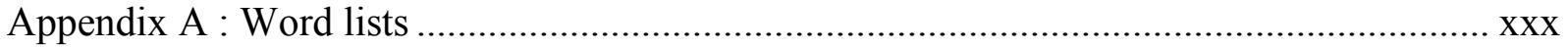

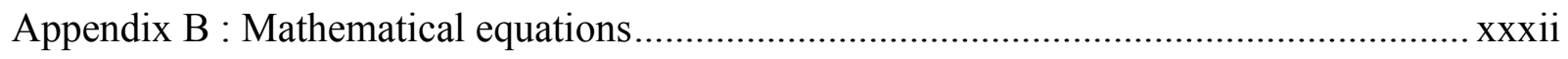




\section{List of tables}

Table I. Characteristics of participants as a function of groups......................................... Xx

Table II. Description of the musical selection. .................................................................. xxi

Table III. Comparison of the three word lists on the words' selection criteria. ................... xxii Table IV. Average number of correct answers in the three series of mathematical equations as

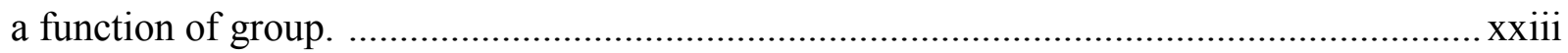

Table V. Average emotional judgements of the musical excerpts in each group. .............. xxiv 


\section{List of figures}

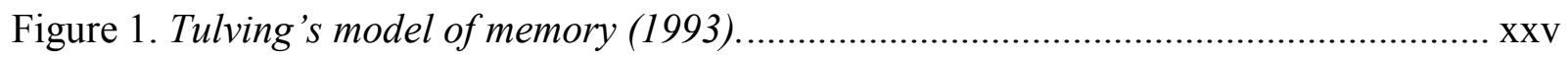

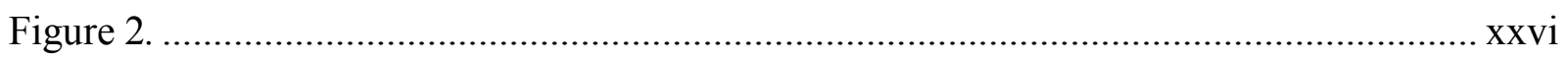

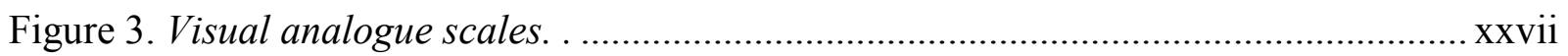

Figure 4. Correlation between the global IQ scores and the average number of words recalled.

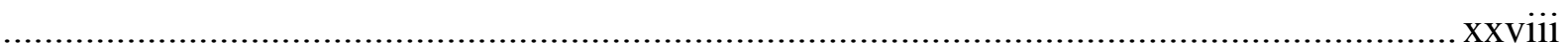

Figure 5. Average number of words recalled per list as a function of groups. ................... xxix 


\section{List of abbreviations}

ANCOVA : Analysis of covariance

$\mathrm{db}:$ Decibels

Etc. : Etcetera

$\mathrm{Hz}:$ Hertz

IQ : Intellectual quotient

$\mathrm{M}:$ Mean

min. : minutes

N/A : Not applicable

SD : Standard deviation

sec. : seconds

SPSS : Statistical Package for Social Sciences 


\section{Introduction}

Although music has always been present in the world, the increased availability, complexity and portability of electronic devices renders music more available than it has ever been. As such, not only is music extremely present in the lives of younger generations, young adults also report that music listening is the most important leisure activity in which they engage daily (Lonsdale \& North, 2011). Specifically, university students aged between 18 and 24 years old report listening to music for 3.66 hours per day on average, while the most passionate music fans listen to music for up to 40 hours per week (Choi, 2003; Lonsdale \& North, 2011; Greasley \& Lamont, 2009). The importance of music to younger adults finds further support in an experience sampling study revealing that participants contacted at random time intervals were listening to music 50\% of the time (Greasley \& Lamont, 2011). While young adults demonstrate clear dedication to music listening, such an important amount of time makes it obvious that music listening occurs in a wide variety of contexts.

Importantly, music listening is not only experienced as a primary activity but additionally occurs during the performance of other activities as well (Calderwood, Ackerman, \& Conklin, 2014). In fact, research shows that music listening is most often secondary to other activities such as studying, driving and cleaning (Stratton \& Zalanowski, 2003; Watson \& Mandryk, 2012). Specifically, a study showed that music listening is best described as background music $76 \%$ of the time (Lonsdale \& North, 2011), where background music is defined as any music which is not the main focus of attention but is present while the listener performs a primary activity (e.g. Bottiroli, Rosi, Russo, Vecchi, \& Cavallini, 2014).

Indeed, numerous activities are regularly accomplished in the presence of background music (e.g. cleaning, reading, driving; North, Hargreaves, \& Hargreaves, 2004). Among those, it was shown that background music is present in up to $71 \%$ of the time dedicated to the performance of cognitive activities such as studying, reading and writing (Stratton \& Zalanowski, 2003; Greasley \& Lamont, 2009). In support of this, a study showed that 59\% of university students were listening to background music while studying (Calderwood, Ackerman, \& Conklin, 2014). While studying involves a range of cognitive processes going from attention to the recall of stored information, a primary goal of studying is to learn and 
remember information for later use. Accordingly, the objective of this study is to explore the effect of background music on long-term memory.

\section{Long term memory}

Before an information becomes stored in the long-term memory, it is essential that it is first processed through the short-term memory. One influent model of such processing is the multi-store model of memory (Atkinson \& Shiffrin, 1971). According to this model, shortterm memory is limited in the number of items it can store simultaneously (e.g. for word lists, we expect an average capacity of seven words). The retention of information in the short-term memory is also limited in time, lasting between 15 and 30 seconds when we lack the possibility to employ strategies to maintain the information within short-term stores (i.e. rehearsal). This justifies that long-term memory experiments, as will be demonstrated later, often include a distractive task (e.g. arithmetic) administered after the learning of information and which duration extends beyond this time interval. Beyond this duration and in the case in which rehearsal is not possible, it is likely that the items recalled have been moved towards long-term memory processes (Atkinson \& Shiffrin, 1971). The specificities of this model are included in the memory task of the current study to ensure that it indeed evaluates long-term memory.

While the multi-store model (Atkinson \& Shiffrin, 1971) does not explain in-depth processes of the long-term memory system, other researchers formulated extensive models of long-term memory. However, there is no consensus on the definition of long-term memory in the various conceptual frameworks offered (e.g. Bahrick, Bahrick, \& Wittinger, 1975; Tulving, 1972; Cohen \& Squire, 1980). To elaborate the current study, we selected Tulving's model (1985, 1993, see Figure 1 for an illustration), a widely-accepted model of long-term memory that is still supported in contemporary research (e.g. Dickerson \& Eichenbaum, 2010). According to this model (Tulving, 1985), long-term memory contrasts with short-term memory in that its capacity is unlimited and the information may remain available indefinitely. Furthermore, the information consolidated into long-term memory is placed into distinct longterm memory systems (e.g. declarative memory) based on the nature of the information (Tulving, 1985). For example, the model suggests that a particular information falls under the 
category of long-term declarative memory when the encoding and recalling of this information requires conscious behavioral and cognitive efforts (e.g. studying).

Declarative memory further divides into two distinct sub-systems, namely semantic and episodic memory. These two sub-systems differ in their content and in the level of spatiotemporal awareness which accompanies the storage and the recalling of their respective information. Indeed, semantic memory concerns general knowledge (e.g. name of colors) and word meanings (e.g. knowing how to use a phone), without regards to the context in which the information was learned. For example, we know that grass is green, and the accuracy of this fact remains unchanged regardless of the context in which this information is presented. In other words, semantic memory has to do with objective facts (Tulving, 1972). This contrasts with episodic memory which involves that subjectively experienced events or episodes (e.g. a wedding day) are encoded along with the specific spatiotemporal context in which these episodes are experienced (e.g. time and place), as further elaborated in the following section.

\section{Tulving's model of episodic memory}

As mentioned previously, Tulving's concept of episodic memory (Tulving, 1972, 1993) falls under the category of long-term declarative memory, in which the successful encoding of information requires that conscious awareness and efforts be directed towards the learning of the information. Furthermore, the specific subsystem of episodic memory is characterized by the subjective experience of events and their accompanying spatiotemporal contexts (Tulving, 1993). This spatiotemporal context is thought to be encoded along with the event or episode and may influence the quality of the learning process and the later capacity to recall the information (Tulving, 1993). In other words, episodic memory implies that information is encoded and recalled within a specific temporal frame, meaning that there is a start and an end to the episode. Again, this contrasts with semantic memory since general knowledge is not necessarily learned nor meant to be used in a known time and place (Hasselmo, 2012).

Specifically, one process involved in the encoding of an episodic memory was termed a "travel forward" and involves conscious efforts to learn information in prevision of later use, according to Tulving (1993). This implies that the learning of information (e.g. word lists) is accompanied by a temporal awareness that the information is meant to be learned and then 
recalled within a precise context and time, as is the case when students are studying for a particular exam. The contextual information and details (e.g. place where the information was learned, music played while studying) are also part of episodic memories and of their longterm storage. As a result, episodic memories are a collection of information from events that occurred in a subjective experience, though they may not be otherwise related, and are stored as a single episode (Tulving, 1993).

Episodic memory also implies a "travel backward" period when recalling previously learned information. When recalling information from episodic memory, it is as if the past episode was being re-experienced and implies the recollection of information in its context. As such, precise details can be retrieved more readily when information is presented within a specific context (Hebert \& Burt, 2003). This highlights the determining role of the context in which information is learned.

While we may think of various real-life examples of episodic memories (e.g. wedding), the study of episodic memory requires that we control the context in which memories are formed. In laboratory settings, episodic memory is most often simulated by asking participants to learn lists of items (e.g. words) and to recall as many items as possible (e.g. in the form of a free recall) after a distraction phase (e.g. Peterson \& Mulligan, 2012; Ford, Morris, \& Kensinger, 2014; Whiffen \& Karpicke, 2017). These types of tasks are measures of episodic memory because they involve strong spatiotemporal components (Hasselmo, 2012). Indeed, a delayed free recall memory task is characterized by the start and the end of a learning phase, followed by the effort to recall the information learned within this unique time interval in a delayed recall phase. Moreover, the multiple phases composing a delayed free recall task (e.g. learning, recall) offer the opportunity to manipulate the environment (e.g. sound condition) that accompanies either one or many of those phases, which reinforces the contextualization of the memory task, and accordingly, the inclusion of contextual information in the formation of episodic memories (Hasselmo, 2012). Furthermore, Tulving (1985) suggested that though other methods are available to evaluate episodic memory (e.g. item recognition; Ferreri, Aucouturier, Muthalib, Bigand, \& Bugaiska, 2013), the free recall of previously learned lists of information (e.g. words) is a more valid measure of episodic memory because the lack of cues in the recall phase demands that the previous learning context be re-experienced, as supported by Perner and Ruffman (1995). 
Given the spatiotemporal nature of episodic memory, it is generally accepted that regardless of the format of the episodic memory task, providing an enriched context to learn and store new episodes facilitates the processing and the long-term storage of the information (for a review, see Souchay, Guillery-Girard, Pauly-Takacs, Wojcik, \& Eustache, 2013). Though the tasks may differ, the learning phase is often the target of experimental manipulations to answer such specific research questions (e.g. Erk et al., 2003; Brierley, Medford, Shaw, \& David, 2007; Schwabe \& Wolf, 2010). Recent studies suggested the use of background music as a potentially beneficial learning context (Ferreri, Aucouturier, Muthalib, Bigand, \& Bugaiska, 2013; Ferreri et al, 2014).

\section{Effect of background music on episodic memory}

Some studies have observed the impact of background music on the performance of different types of episodic memory tasks. Before we discuss them, we highlight that the background music selection varies across the following studies and particularly the musical parameters (e.g. mode, tempo), some of which are thought to alter the listeners' emotional states (Gomez, Danuser, \& Phelps, 2007; Zwaag, 2011; Fernandez-Sotos, FernandezCaballero, \& Latorre, 2016). As will be demonstrated, it is possible that these changes in emotional states in turn influence the episodic memory performances. Thus, the description of those musical parameters along with the understanding of their emotional effects deserve further attention and are discussed in the Emotional regulation and musical emotions section.

Regarding the episodic memory tasks, a typical observation across the following studies is that they are generally constructed in three distinct phases. Namely, the learning phase consists of asking participants to memorize lists of items in the presence of an auditory context. The learning phase is followed by a distraction phase which role is to prevent the rehearsal of the previously learned items. The episodic memory task is completed in a retrieval phase. The later may take different forms including recognition memory (i.e. asking participants to identify the previously learned items among series of old and new items), and free recall (i.e. asking participants to recall the previously learned items without any cue, in any order). 
Early studies observed the influence of background music on episodic memory performances using different visual stimuli. For example, Boltz, Schulkind, and Kantra (1991) showed that the presence of happy and sad background music, as expressed in musical pieces composed in major and minor modes respectively, increased the amount of visual details of non-vocal filmed events in a later free recall. However, this effect was only seen when the musical emotion was congruent with the emotion expressed in the scene (i.e. when they were both perceived as being either happy or sad). In another study, Furnham and Allass (1999) observed the effect of simple and complex background music compared to silence on memory for series of images. The musical selection was classified as simple or complex based on specific qualities such as tempo and melodic complexities. This study showed that the presence of either types of background music had no effect on the delayed recall of images compared to silence.

More recently, a study from Proverbio and colleagues (2015) supported a potential influence of emotionally charged music on memory. In this study, participants were asked to recognize faces which had been previously presented and memorized in the context of either music, rain sounds or silence. Participants performed better in recognizing faces which had been presented along with background music compared to faces presented with rain sounds and silence. Importantly, the music seemed to increase participants' arousal levels (i.e. they experienced an increased stimulation) as demonstrated by their increased heart rate during the learning phase, which may contribute to explain its facilitative effect on memory compared to the rain sounds and silence conditions. This possibility was further explored in episodic memory with verbal material.

In the context of episodic memory with verbal material, a group of researchers observed the number of words that were recalled by participants in different auditory conditions (fast and slow music, and noise, Jäncke \& Sandmann, 2010). Musical excerpts were composed in a slow and fast tempo by the researchers to simulate relaxing and stimulating background music and were compared to a control noise condition created from the frequencies found within the composed musical excerpts. The learning phase consisted of memorizing words while listening to music or noise. This was followed by an eight-minute rest and then a recognition memory phase in which series of old and new words were presented. Neither enhancing nor detrimental effects of music or noise were found on the 
number of words correctly identified. One possible explanation is that participants could rehearse the previously learned words during a prolonged period given that there was no specific distractive task to do during the rest phase. Thus, rehearsal may have had a beneficial effect confounding with that of background music.

Other researchers have demonstrated a positive impact of background music on memory for word lists. In a study from Tesoriero and Rickard (2012), participants listened to stimulating (happy or fearful) or non-stimulating (sad or calm) background music, selected from previous studies for efficiently inducing the targeted arousal levels. Then, they listened to a short narrative and freely recalled its details after a five-minute distraction phase consisting of identifying the content of neutral images. Their results showed that participants recalled a greater number of details when narratives were preceded by arousing music (i.e. happy and fearful), compared to musical excerpts displaying low arousal levels (i.e. sad and calm). However, there were no non-musical auditory stimulus to compare these results with. As such, it remains difficult to affirm that the improvement in episodic memory is specific to the presence of music. Yet, these results suggest that musical emotions potentially influence the effect of background music on episodic memory.

Another researcher observed the effect of background music on learning words of a foreign language (De Groot, 2006). In this study, participants learned word lists in the presence of moderately arousing music or in silence and performed a recognition memory task one week after the learning phase. This study demonstrated that participants who learned the words in the presence of music compared to silence performed better on the later recall phase (i.e. they recalled a greater number of words), which supports that an arousing context provided by the presence of music may be beneficial to episodic memory.

Furthermore, a recent study asked participants to learn word lists in the presence of background music and in silence (Ferreri, Aucouturier, Muthalib, Bigand, \& Bugaiska, 2013; Ferreri et al., 2014). The selected music was pleasant and moderately stimulating, as evaluated by the research team. After a ten-minute distractive task, series of old and new words were presented to the participants who were asked to identify the previously learned words along with the context in which they were learned (i.e. music or silence). Results showed an increase in the number of words recalled when they were learned in the context of background music compared to those learned in silence (Ferreri, Aucouturier, Muthalib, Bigand, \& Bugaiska, 
2013; Ferreri et al., 2014). As demonstrated by a decreased activity in neurophysiological measures associated with memory formation, these results suggest that the presence of music decreased the amount of efforts required to encode the words due to the presence of a facilitating context (i.e. background music; Ferreri et al., 2014).

Yet, equally numerous researchers found no effect of background music on episodic memory for word lists compared to silence (Behne, 1999; Jäncke \& Sandmann, 2010; Jäncke, Brügger, Brummer, Scherrer, \& Alahmadi, 2014). For example, Jäncke, Brügger, Bummer, Scherrer, and Alahmadi (2014) observed the effect of vocal and instrumental background music on episodic memory for word lists compared to silence. The musical excerpts varied in terms of arousal (i.e. relaxing or stimulating) and were equally pleasant. Results showed that groups' performances on the memory task did not differ from each other. However, the recall phase in this study occurred two weeks after the learning phase. This prolonged period might have resulted in the impossibility to maintain a certain control over the participants' emotional changes.

Generally, results vary from one study to another, possibly because the methods used to examine episodic memory differ across studies. To optimize those results, it is important to select an appropriate measure of episodic memory. Since the current study targets university students, the task also has to be adapted to their elevated cognitive capacities. Among the presented methods available to investigate episodic memory in university students, the learning of word lists and their free recall is one of the most frequently used in music and memory research (e.g. De Groot, 2006; Cassidy \& MacDonald, 2007; Jäncke \& Sandmann, 2010; Ferreri, Bigand, Bard, \& Bugaiska, 2015). A free recall, compared to other recall methods such as recognition, may be more adapted to university students because of its increased difficulty level and the greater likelihood that it will prevent ceiling effects (Kintsch, 1970). Furthermore, as mentioned earlier, it was suggested that free recall performances require that participants re-experience mentally the previous learning context in order to facilitate the recall of information. Thus, considering their precise spatiotemporal contexts, free recall tasks are thought to be adequate measures of episodic memory (Tulving, 1985; Perner \& Ruffman, 1995). With this in mind, a group of researchers adapted an episodic memory task to study the effect of background music on episodic memory in university students and particularly inspired the methods of the current study because it has been 
validated and adapted multiple times in previous studies (e.g. Ferreri, Bigand, Bard, \& Bugaiska, 2015; Ferreri, Aucouturier, Muthalib, Bigand, \& Bugaiska, 2013; Ferreri et al, 2014).

The episodic memory task used by Ferreri, Bigand, Bard, and Bugaiska (2015) consisted of three 15-word lists, each presented in three successive phases: learning, distraction and retrieval. In the learning phase, a 15-word list which words were presented successively for three seconds each was presented on a computer screen. The auditory context (i.e. music or silence) was presented 15 seconds prior to the presentation of the first word, continued during the word presentation and ended 15 seconds after the last word disappeared. The reason for extending the length of the excerpt was to habituate participants to the auditory background so that it is not new during the word presentation. This procedure also allowed to stabilize emotional responses evoked by the auditory excerpt (e.g. startle). By the end of the auditory background or silence, participants were asked to count backwards for 30 seconds (i.e. distraction phase) in order to prevent the rehearsal of the previously learned words. In the final retrieval phase, participants were asked to freely recall aloud all the words they could remember from the previously learned list, without any contextual cue and in silence. Finally, they were given a 30 -second break before this procedure was repeated with a second and a third word list. They found that background music did not increase the number of words recalled per se, but increased the number of words recalled in the order in which they were learned compared to silence (Ferreri, Bigand, Bard, \& Bugaiska, 2015).

Though Ferreri, Bigand, Bard, and Bugaiska (2015) demonstrated no effect of background music compared to silence on the number of words recalled, it is possible that the distractive task was too short to essentially capture episodic memory. Rather, episodic memory is part of long-term memory and 30 seconds may not be sufficient to transfer information from short-term to long-term memory (Atkinson \& Shiffrin, 1971). Hence, while the later task is well controlled, it could be beneficial to extend the time interval between the learning and the recall phases to make sure that we capture the targeted episodic memory system. This episodic memory task and the latter suggestion are applied in the current study (see Figure 2).

Briefly, there is some support for an influence of background music on episodic memory, yet results regarding how background music influences the performance of episodic 
memory tasks remain unclear. Indeed, results are very heterogeneous and comprise as many beneficial, impairing and null effects of background music on episodic memory performances (Kampfe, Sedlmeier, \& Renkewitz, 2010). Importantly, most of the above discussed studies include at least one of the following limitations, which may account for the heterogeneity among those results. These limitations pertain to the low control over the musical selection, to the lack of appropriate control groups and to the lack of control over individual differences among participants.

\section{Musical selection}

An important problem frequently encountered in literature is that music is often treated as a unidimensional stimulus. Given that music is very complex in nature (e.g. rhythm, melody, tempo, mode, volume), it is important to control for its dimensions very strictly in order to know whether either one or many of them have an effect on cognition. However, auditory excerpts are often selected and evaluated subjectively by the experimenter or a small research team as possessing certain characteristics (e.g. stimulating; Ferreri, Aucouturier, Muthalib, Bigand, \& Bugaiska, 2013; Ferreri et al., 2014). Musical excerpts may even be created according to the experimenter's beliefs and perceptions (Jäncke \& Sandmann, 2010). These selection techniques are questionable in that individuals' experience of the music is influenced by a variety of personal factors (e.g. familiarity; Juslin \& Västfjäll, 2008) which have the potential to affect episodic memory differently from an individual to another. Thus, to suggest that a specific musical dimension is responsible for an effect on episodic memory performance, it is essential to control for the various musical dimensions more objectively.

\section{Group selection}

Importantly, whether background music influences episodic memory directly or indirectly (e.g. through emotion induction) is unclear in past research. Yet, if the latter suggestion were true, other non-musical auditory stimuli should also influence performances on episodic memory tasks. Indeed, music is not unique in inducing emotions and this suggestion highlights the importance of providing comparable control groups, which failed to be included in many studies. Namely, most of the previously discussed studies compared an experimental group which consists of performing an episodic memory task in the presence of 
background music to a non-auditory silence group in which the cognitive task is performed in silence. However, a significant effect discovered in these circumstances does not specify whether it is music or the mere presence of an auditory stimulation that accounts for the effect, nor does it allow to manipulate or isolate specific parameters (e.g. slow and fast tempo) to observe their potentially distinct effect. For example, a group of researchers observed that cognitive tasks were performed more successfully when accomplished in the presence of a classical background music compared to when they were performed in silence, yet music was no longer beneficial when compared to a non-musical auditory background (i.e. a story; Nantais \& Schellenberg, 1999). This finding supports that music may not be unique in benefiting cognitive performances and supports that a musical stimulus should be compared against a non-musical auditory stimulus (e.g. noise).

\section{Individual differences}

Another limitation in past research is the lack of control over individual differences. While many variables could account for differential performances on episodic memory tasks, it is well documented that intellectual quotient (IQ) has an impact on learning and recalling episodic memories. Accordingly, Chamorro-Premuzic and Furnham (2007) explored episodic memory performances in different contexts and have shown significant results only when IQ was controlled for. This means that, holding equal IQ scores across groups of participants, these researchers observed greater group differences. Moreover, individuals with higher IQ scores are more likely than those with lower IQ scores to use background music during the performance of their cognitive activities (Alexander \& Smales, 1997; Chamorro-Premuzic \& Furnham, 2007), which may imply that IQ influences how we monitor the presence of background music during the performance of cognitive activities. For these reasons, it is important to observe the effect of background music on episodic memory while controlling for IQ, because its effect on the performance of episodic memory tasks could differ according to IQ levels.

Despite these limitations, it is important to note that in the literature, different results were obtained from the manipulation of various musical emotions (e.g. happy, sad, arousing, relaxing) and of parameters known to influence the emotional responses of the listener (e.g. 
tempo, mode; as described in the following section). Thus, it is possible that various emotional and structural parameters within background music influence episodic memory differentially. For this reason, it is crucial to examine the effect of background music on episodic memory in the light of its effect on emotions.

\section{Effects of background music listening}

A study suggested that most students (97\%; North, Hargreaves, \& Hargreaves, 2004) who listen to background music while studying report that background music positively affects their performances on the concurrent activity. In the light of the previously discussed results, it is likely that these perceived effects are indirect. Namely, the most common reason for listening to music is for emotional regulation (e.g. increased activation; Hargreaves \& North, 1999; Chamorro-Premuzik \& Furnham, 2007; Schäfer \& Sedlmeier, 2009; Lonsdale \& North, 2011). Accordingly, it is plausible that music influences the listeners' emotions, which in turn may alter cognitive performances. The ways in which music alters the listeners emotions are described in this section.

\section{Emotional regulation and musical emotions}

Literature has consistently supported that music can effectively modulate emotions (e.g. improve mood; Juslin \& Sloboda, 2001; Juslin \& Vastfjall, 2008; Greasley \& Lamont, 2011). Indeed, many studies demonstrated that specific musical parameters (e.g. tempo, mode) play important roles in determining our emotional responses to music (Gomez, Danuser, \& Phelps, 2007; Zwaag, 2011; Fernandez-Sotos, Fernandez-Caballero, \& Latorre, 2016).

One initiator of emotional modulation through music listening is the perception of the emotion expressed in the musical excerpt, as examined using self-reports (Vieillard, et al., 2008). Those perceived musical emotions tend to vary based on specific musical parameters (Danna Bella, Peretz, Rousseau, \& Gosselin, 2001; Straehley \& Loebach, 2014). For example, it was shown that slow tempo music is most often perceived as being relaxing compared to fast tempo music which is most often perceived as being stimulating (Iwanaga \& Moroki, 1999; Juslin \& Sloboda, 2001; Gabrielsson \& Lindstrom, 2003; Rickard, 2004; Ilie \&

Thompson, 2006; Wang, 2014). Moreover, a music composed in a major mode tends to be 
perceived as pleasant regardless of the tempo (Digiacomo \& Kirby, 2006; Suda, Morimoto, Obata, Koizumi, \& Maki, 2008).

Importantly, musical emotions may also be observed through physiological responses (e.g. increased heart rate) that often occur during the mere listening of emotionally charged music. As a result, listeners may feel internally in a way that is concordant with the emotions expressed in the music (Gomez \& Danuser, 2007; Van Der Zwaag, Westerink, \& Van Den Broek, 2011). For example, listeners tend to experience increased physiological arousal levels when exposed to stimulating music composed in a major mode (Gomez \& Danuser, 2007; Guhn, Hamm, \& Zentner, 2007; Lundqvist, Carlsson, Hilmersson, \& Julsin, 2008; Van Der Zwaag, Westerink, \& Van Den Broek, 2011; Russo, Vempala, \& Sandstrom, 2013).

Accordingly, research suggested that both perceived musical emotions and physiological responses may be influenced by the presence of music, and both types of responses generally concord with each other (Blood, Zatorre, Bermudez, \& Evans, 1999; Blood \& Zatorre, 2001). For example, research shows that when listening to stimulating background music, the listeners' arousal level significantly increases compared to prior music listening, as demonstrated in both subjective (e.g. self-report) and objective (e.g. psychophysiological) measures (e.g. Thompson, Schellenberg, \& Husain, 2001; Schellenberg, Nakata, Hunter, Tamoto, 2007). Similarly, listening to relaxing music was shown to be effective in decreasing the listeners' arousal level according to similar subjective and objective measures (Labbé, Schmidt, Babin, \& Pharr, 2007; Van Dyck, Six, \& Leman, 2016). Thus, there is empirical evidence supporting that the manipulation of musical parameters likely results in the induction of emotions, including various arousal levels and moods.

Despite controlling for those parameters, musical emotions can be felt differently by persons who have different experiences related to the music (e.g. preferences). As such, a solution to select musical characteristics more objectively with regards to emotions is to ask participants to make emotional judgements about a variety of musical excerpts hence allowing us to select the excerpts that are evaluated as owning the characteristics that we wish to manipulate (e.g. stimulating or relaxing music). The current study used this technique to select the musical excerpts presented during our episodic memory task according to the characteristics of arousal level (stimulating or relaxing), and of emotional valence (pleasant or 
unpleasant). Specifically, we wished to select stimulating and relaxing musical excerpts which were equally pleasant, given that a recent study demonstrated that background music facilitated episodic memory performances only when it was emotionally rewarding (i.e. pleasant) to the listeners (Ferreri et al., 2017). The same emotional judgements about the auditory selection were also evaluated by the participants themselves. Though the effect of various musical parameters remains to be explored in the context of episodic memory, there is evidence to support the influence of musical emotions in the domain of cognition at large.

\section{Mood arousal theory}

The mood arousal theory suggests that music may benefit cognitive performances by inducing emotions. Specifically, this theory posits that it is the induction of positive moods and of increased physiological arousal that could help improving cognitive performances (Thompson, Schellenberg, \& Husain, 2001).

Years ago, researchers believed that background music had a direct impact on cognitive performances, some of whom reported that cognitive performances were improved following the listening of Mozart's music (Rauscher, Shaw, \& Ky, 1993). Indeed, this was suggested after observing an improvement in the performance of cognitive tasks when they were performed after listening to Mozart's music compared to silence. While the improved cognitive performances were entirely attributed to Mozart's music, whether the effect was specific to the music or extended more broadly to any arousing auditory stimulus was unknown. Indeed, no non-musical auditory stimulus was provided to control for some of the multiple musical dimensions (e.g. emotions) which could be responsible for producing this effect.

For this reason, other researchers replicated this study by including a non-musical auditory control group (i.e. listening to a story) displaying equally positive emotions and similar levels of arousal as those presented in Mozart's music (Chabris, 1999; Nantais \& Schellenberg, 1999; Thompson, Schellenberg, \& Husain, 2001). The cognitive performances on spatial tasks were measured following the listening of those auditory stimuli. Their results demonstrated that groups were no longer different in their performances. Thus, the improved 
cognitive performance following classical music listening was described as an artifact of mood and arousal (Thompson, Schellenberg, \& Husain, 2001).

As such, it appears that music is not unique in influencing cognition, which suggests that it is not the music per se that has an effect but rather the emotions that it induces, through mood and arousal in particular. Consequently, other non-musical stimuli may induce similar emotions as music and could have similar effects on cognition. As such, it is important to provide a non-musical auditory control stimulus to which we can compare the effect of background music on a certain task. Such manipulations remain to be explored in the context of episodic memory. To avoid that the background stimulus interferes with the learning of words it is preferred to use non-verbal types of auditory stimulation (Salamé \& Baddeley, 1982). Namely, research supports that continuous background noise could be effective in increasing arousal levels (e.g. Salamé \& Baddeley, 1982; Söderlund, Sikström, \& Smart, 2007; Szalma \& Hancock, 2011).

Among the few studies which observed the effect of noise on cognition, white noise has received particular attention (Surprenant \& Neath, 1996; Surprenant, 1999; Hygge, Boman, \& Enmarker, 2003; Boman, Enmarker, \& Hygge, 2005). White noise is a continuous noise, similar to that of machinery sounds (e.g. air conditioning), combining all frequencies and displaying an equal level of energy upon each individual frequency. Humans can rarely perceive individual frequencies (Bachem, 1955). Rather, sounds are perceived in octaves for most of us. However, octaves vary in the number of frequencies they contain (e.g. lower octaves include much less frequencies than higher octaves). As a result, more energy is attributed to higher octaves. This explains why higher octaves in white noise are perceived as being more intense than lower octaves (Bottiroli, Rosi, Russo, Vecchi, \& Cavallini, 2014).

Some researchers argued that white noise impairs performances in comparison to silence, but less so than distractors like speech (Surprenant \& Neath, 1996; Surprenant, 1999). Though these results do not show a positive effect of noise on episodic memory, the possibility that its effect is greater than that of speech is eloquent. Others demonstrated that white noise was effective to increase concentration in a memory task and thus improved performances, but only when the volume of the noise was at a moderate level as opposed to elevated (Söderlund, Sikström, Loftesnes, \& Sonuga-Barke, 2010). This suggests that the varying levels of arousal conveyed through different volume levels may have a significant 
impact on episodic memory. However, it is possible that white noise may be evaluated as unpleasant due to the perception of increased intensity in higher frequencies, which may not be an optimal control measure against pleasant musical stimuli (Bottiroli, Rosi, Russo, Vecchi, \& Cavallini, 2014).

In this regard, a logical next step would be to optimize both the control over the frequencies that make up for the noise group along with the perception of the frequencies' intensity level. To do so, it is possible to create a noise from the frequencies found within the musical excerpts selected for the experimental groups and to equalize their intensity so that each octave is perceived as being equally intense. One such promising control noise is the pink noise. Perceptually, pink noise is similar to the white noise in that it is also a continuous sound made of a wide range of frequencies. However, pink noise displays an equal energy level in each octave, regardless of the number of frequencies comprised in the octave (to hear a pink noise example, listen to http://www.audiocheck.net/testtones pinknoise.php). As an effect, higher and lower octaves are equally intense.

The beneficial effect of pink noise in the context of memory for words has also received support from the literature. For example, Skarlatos and Georgiou (2001) showed that pink noise can positively affect memory for text when played below $92 \mathrm{db}$ compared with daily environmental background noise (e.g. traffic). Above this level, performance decreased, possibly due to the too elevated arousal induced by loud noises. This indicates that background music may not be unique in benefiting cognitive performances, as long as arousal levels are controlled. The mood-arousal theory guided the current study and is applied in the context of episodic memory.

\section{Objectives and hypotheses}

The current study aims to clarify the role of musical emotions in the effect of background music on the performance of an episodic memory task. More specifically, this study explores the influence of the arousal dimension of music on episodic memory. To do so, three groups of participants performed an episodic memory task consisting of learning lists of words in an auditory context (stimulating or relaxing background music, or noise). To avoid the potential confounding effects of other musical dimensions (e.g. valence), we ensured that 
the selected musical excerpts were equally pleasant. Since IQ is known to influence episodic memory, we also aimed to pay attention to the potential influence of IQ. Thus, IQ was included as a covariable.

According to the mood arousal theory (Thompson, Schellenberg, \& Husain, 2001), we expected that the stimulant group would perform better than the relaxant group. We also predicted that the relaxant group's performance would be lower than that of the two other groups. Finally, we predicted that the noise group's overall performance would range between the stimulant and relaxant groups' performances.

\section{Method}

\section{Participants}

An initial sample of 35 university students was recruited on the campus of the Université de Montréal, as well as on social media (e.g. BRAMS and MUSEC websites, Facebook). Upon written consent, screening questionnaires were administered to include French Quebec natives only. The reason for this inclusion criterion has to do with the nature of the word selection which composes the memory task. Certain words are more readily recalled than others in a free recall task, partly due to their frequency of use (Balota \& Neely, 1980; DeLosh \& McDaniel, 1996; Ward, Woodward, Stevens, \& Stinson, 2003; Hicks \& Marsh, 2005). To control for this possibility, we selected words of a similar frequency of use in the Quebec French language. However, those word frequencies may differ from those of other languages, which could result in difficulty differences between Quebec and non-Quebec natives when memorizing the same words.

As for the exclusion criteria, we limited our sample to non-musicians (i.e. fewer than five years of regular practice of a musical instrument or voice). Participants who suffered neurological, psychological or psychiatric disorders were also excluded from the study based on a self-reported form.

Furthermore, we excluded participants who experience a lack of pleasure from music listening (i.e. musical anhedonia; Martinez-Molina, Mas-Herrero, Rodriguez-Fornells, \& 
Marco-Pallarés, 2015; Bigand et al., 2015). Because we seek to observe the effect of musically-induced emotions, persons who simply do not experience those emotions during music listening may respond differently to the potential effect of musical emotions on cognition compared to those who experience musical reward to a greater extent (Ferreri et al., 2017). We used the French validation of the Barcelona Music Reward Questionnaire (BMRQ; Saliba et al., 2016) to evaluate participants' enjoyment of music listening. Based on the normative factorial scores $(M=50, S D=10)$ of the BMRQ (Mas-Herrero, Pallarés, LorenzoSeva, Zatorre, \& Rodriguez-Fornells, 2013), three participants scored very low on musical reward $(M=34.67, S D=2.89)$. They were thus identified as anhedonics and were excluded from the analysis.

Moreover, persons who experience music perception deficits (i.e. amusia; Peretz et al., 2002) were excluded because they seem to process musical information differently compared to the majority of music listeners (Leveque, Tillman, \& Caclin, 2015; Gosselin, Paquette, \& Peretz, 2015; Zatorre, 2015). Thus, the effect of background music on their episodic memory performances may also differ from that of the general population. Musical perception deficits were evaluated using the Online test of Amusia (Peretz et al, 2008). This test comprises three blocks (to listen, visit http://www.brams.umontreal.ca/onlinetest/). The first block asks participants to judge pairs of musical excerpts as being the same or different. In the second block, participants have to judge the accuracy of the timing of the notes in various excerpts. In the third block, participants have to identify whether musical excerpts contain a false note or not. One participant obtained a total score below $70 \%$ and was excluded from the analysis for being amusic.

Finally, we administered an audiometric test meant to detect auditory impairment. During this test, participants were placed in a soundproof booth and wore headphones. They were asked to press a button each time they would hear a tone. Then, eight pre-selected frequencies ranging from $250 \mathrm{~Hz}$ to $8000 \mathrm{~Hz}$ were played at different volume levels (from 0 to $30 \mathrm{db}$ ) in order to detect the lower threshold of hearing of each participant. As a result, it was possible to evaluate individuals' hearing sensitivity of both right and left ears separately. This auditory test confirmed that none of our participants had auditory problems (i.e. no hearing 
loss exceeding 20\% in 250-8000 Hz; Mahdavi \& Peyvandi, 2007). The final sample included 31 university students.

Participants were randomly assigned to one of the three groups: stimulating or relaxing background music groups (stimulant group, $n=10$ or relaxant group, $n=10$ ), or to the nonmusical auditory control group (noise group, $n=11$ ), in a mixed ANCOVA design. Participants from each group were matched on sex, age, schooling years and musical education (see Table I). Though there were significantly more females than males in the noise group compared to both music groups $(p=.011)$, this ratio was not different from that of the two music groups. Furthermore, a mixed ANOVA of Sex (between-group) and List (withingroup) showed that there was no effect of sex on the number of words recalled per list in the episodic memory task. For this reason, we did not consider the sex factor in the analyses.

Groups were also equal on IQ as evaluated by the French adaptation of the Wechsler Abbreviated Scale of Intelligence (WASI; Wechsler, 1999). General music-related habits were also assessed and confirmed that our sample was representative of the previously reported musical habits in young adults (Choi, 2003; Lonsdale \& North, 2011; Greasley \& Lamont, 2011). Those musical habits were also similar between groups.

\section{Material}

\section{Musical excerpts}

Musical excerpts were selected from a pre-study in which 42 instrumental musical excerpts from the classical repertoire were evaluated by 50 participants according to two emotional dimensions. Namely, participants rated the excerpts on their level of arousal (from 0 $=$ very relaxing to $100=$ very stimulating) and emotional valence (from $0=$ very unpleasant to $100=$ very pleasant), using visual analogue scales (see Figure 3; Tat, Pelletier, Massicotte, \& Gosselin, 2015). From these emotional judgements, we selected three stimulating and three relaxing musical excerpts of equally positive valence (see Table II). As expected, the excerpts evaluated as being stimulating had fast tempi ranging from 145 to 160 beats per minute compared to the relaxing musical excerpts which tempi were significantly slower, ranging from 64 to 96 beats per minute $(p=.005)$. All excerpts were composed in a major mode and 
lasted 75 seconds in order to match the length of the learning phase in the episodic memory task. Finally, the excerpts began with a fade-in and ended with a fade-out to prevent surprise responses. The excerpts' titles and compositors along with their emotional judgements, their tempo and their temporal selection (i.e. the specific excerpt within the musical piece that was selected for this study) are shown in Table II.

\section{Noise}

We created a pink noise from the range of frequencies contained within the six selected musical excerpts. Creating our own pink noise allowed us to provide a more optimal control group which included the same range of frequencies as that found within the musical excerpts listened to by the two experimental groups of participants. The procedure to create our pink noise was twofold.

First, we identified the range of frequencies contained within the six musical excerpts selected for our study. Among the six excerpts, the largest frequency spectrum varied from $0 \mathrm{~Hz}$ to $16000 \mathrm{~Hz}$. This range of frequencies constituted the basis of our pink noise. Secondly, we generated a pink noise made of all frequencies. From this noise, we simply cleared the frequencies above $16000 \mathrm{~Hz}$.

The creation of the noise and the modification of the musical excerpts were achieved using the Adobe Audition software 3.0. All auditory stimuli were played through headphones at around $60 \mathrm{db}$ (Cassidy \& MacDonald, 2007) for 75 seconds each, during the learning phase of the episodic memory task.

\section{Word selection procedure}

We exerted a strict control over the words included in our word lists in order to minimize difficulty differences between the three lists, which could lead to the misinterpretation of our results. The word lists created in the episodic memory task which inspired the task in the current study were originally created based on the words' frequency of use in the European French language (Ferreri, Bigand, Bard, \& Bugaiska, 2015). To adapt the task to our study, we developed three new word lists based on the word frequencies in the Quebec French language. To ensure that the lists are as similar as possible, numerous criteria 
were considered in the selection of the words composing the lists. These criteria are discussed in this section and the comparisons of the three word lists on each criterion are shown in Table III.

First, only the nouns of a high frequency of use were considered because they are more readily recalled (Baddeley \& Scott, 1971). The dictionary of word frequency of the Quebec French language (Beauchemin, Martel, \& Théoret, 1992) was used to select the words based on their frequency of use per million word occurrences. The selected words were assigned to one of the three lists so that the resulting average frequency of the three lists is not significantly different from each other.

A second selection criterion was that of concreteness. Indeed, only concrete nouns were included in the lists. To ensure that all nouns were equally concrete, we referred to a study of Bonin and colleagues (2003) in which French words were evaluated on their level of concreteness on a scale from 1 (not concrete at all) to 5 (very concrete). Because concrete words are more easily recalled, we selected the words which had the highest ratings on concreteness (i.e. rated 4 or 5). As a result, words like "balai" $(M=4.77)$ were allowed in our selection, whereas words like "monde" $(M=2.55)$ were excluded. This allowed us to validate that the remaining words are generally accepted as being highly concrete.

A third criterion of imageability ensured that all the words could be easily imagined. A study from Desrochers and Bergeron (2000) asked hundreds of participants to evaluate French words in terms of how well they can imagine them, on a scale from 1 (not at all) to 7 (very easily). Only the words evaluated as easily imaginable (6 or 7) were included in the lists.

As a fourth criterion, we considered the emotional valence of the words (i.e. pleasant or unpleasant). It is well established that memory for emotional words vary according to participants' inner feelings (Doerkson \& Shimamura, 2001; Kensinger \& Corkin, 2003). Since music may induce emotions in some listeners, we wished to minimize the potential interaction between the musical emotions and the emotional valence of the presented words. As such, only the words evaluated as having no emotional value were selected. To achieve this, we examined the emotional evaluations of French words reported in Bonin and colleagues' study (2003). In this study, participants evaluated words as being either negative (1) or positive (5). 
Thus, only the words evaluated from 2.5 to 3.5 were selected in our lists, so that each list contains non-emotional words only.

Finally, we ensured that the length of the words was equal between each list. The length was measured in terms of the number of written syllables in each word, because the words were presented visually rather than auditorily. Words were assigned so that each list contains an equal number of words with a particular number of syllables, varying between two and three syllables. This criterion was set because shorter words are easier to recall compared to longer words (Baddeley, 1975).

In summary, the three word lists were equal in terms of frequency of use, word concreteness, imageability, emotional valence and length. The three final word lists are shown in Appendix A.

\section{Musical emotional judgements}

Immediately after the end of the episodic memory task, all participants listened again to the three auditory excerpts that they had been presented during the memory task and were asked to evaluate them according to two emotional judgements. Specifically, they had to report the arousal level (from $0=$ very relaxing to $100=$ very stimulating) and emotional valence (from $0=$ very unpleasant to $100=$ very pleasant) of each auditory stimulus, using visual analogue scales (see Figure 3). These ratings allowed us to confirm that the emotions (e.g. arousal level) in the selected excerpts were perceived as intended by the participants.

\section{Other measures}

The French version of the Wechsler Abbreviated Scale of Intelligence (WASI; Wechsler, 1999) was used to ensure that the three groups of participants were similar on global intelligence and to control for the influence of IQ in the effect of background music on episodic memory. The WASI is a reliable and brief measure of intellectual quotient which provides a global IQ score based on four subtests. In the vocabulary subtest, participants are asked to define 42 items (pictures and words). In the similarities subtest, participants are asked to identify commonalities between 26 pairs of words (e.g. plane and bus: means of transportation). In both verbal subtests, scores are attributed based on the specificity of 
participants' answers ( $0=$ unspecific to $2=$ very specific $)$. In the block design test, the experimenter presents 13 white and red designs which are to be reproduced by the participant using the top of white and red blocks. Participants are awarded points based on the speed with which the designs are accurately reproduced. The final subtest is a matrix reasoning test and consists of showing participants 35 matrices in which a piece is always missing. Participants are asked to identify which one among five optional drawings is meant to complete the original matrix. Finally, the scores obtained on each subtest are converted into a global IQ score by using the conversion tables of the WASI manual.

\section{Procedure}

Upon consent, voluntary university students completed online questionnaires prior to the appointment which allowed us to confirm the eligibility of each participant. The participation in this study occurred in a single individual session lasting around two hours, in a soundproof booth at BRAMS Laboratory. On appointment day, we administered an auditory test to confirm that participants had no auditory problems. Participants then performed the episodic memory task as follows. As mentioned earlier, the current episodic memory task is concordant with Tulving's model of long-term memory (Tulving, 1985). Thus, we refer to the term episodic memory to describe the following task, as was used to describe similar tasks in other recent studies from known researchers on long-term episodic memory processes (e.g. Clément, Belleville, \& Mellah, 2009; Ferreri et al., 2014; Ferreri, Bigand, \& Bugaiska, 2015).

An episodic memory task for word lists created by Ferreri, Bigand, Bard, and Bugaiska (2015) was adapted for our study. The overall task was made of three word lists which each comprised three consecutive phases: learning, distraction and free-recall (see Figure 2). The learning phase consisted of memorizing 15 words appearing successively and paced at three seconds per word on a computer screen. The auditory stimuli started 15 seconds before and ended 15 seconds after this learning phase in order to limit surprise effects. Participants were instructed to memorize as many words as possible in any order and to ignore the auditory context. The learning phase was immediately followed by the distraction phase which consisted of completing simple mathematical equations (e.g. $21 \div 7$; see Appendix B) for two minutes. Finally, in a free-recall phase, participants had 60 seconds to recall aloud all the 
words they could remember from the previous learning phase, in any order. After a 30-second rest, the memory task was performed again with a second and then a third list. In this task, the performance was measured by the number of words correctly recalled per list. The order of the three musical excerpts accompanying each list varied randomly from a participant to another. At the end of the experiment, participants were asked to listen again to each of the auditory excerpts heard during the episodic memory task and to rate them on visual analogue scales according to two emotional dimensions (arousal level and valence). Both tasks were administered using E-prime software (Psychology Software Tools, 2012). The experiment ended with the WASI. Participants received a monetary compensation for their participation.

\section{Design and data analysis}

The design of this study is a mixed analysis of covariance (ANCOVA). A mixed design helps to reduce tiredness and practice effects. Additionally, given the multiple strict criteria applied in the word selection of the episodic memory task, it would not have been possible to create a sufficient number of word lists meeting every criterion in an entirely within-subjects design (i.e. three conditions with three lists per condition). Furthermore, the three word lists were analyzed separately rather than compared on their average. It is wellknown that listening to music tends to induce emotions that are concordant with those expressed in the music (e.g. happiness; Gomez \& Danuser, 2007; Guhn, Hamm, \& Zentner, 2007; Lundqvist, Carlsson, Hilmersson, \& Julsin, 2008; Van Der Zwaag, Westerink, \& Van Den Broek, 2011; Russo, Vempala, \& Sandstrom, 2013). However, it is unclear how long of an exposure to those musical emotions is required to actually induce one. Yet, this delay likely varies from one individual to another, and the intensity of emotional induction seems to increase over the prolonged exposure to musical stimuli which display similar emotional characteristics (Eich \& Metcalfe, 1989; Carr \& Rickard, 2016). Such variations in the intensity of emotional induction could result in differential episodic memory performances across trials. To account for this possibility, it is preferable to analyze the three lists separately in order to avoid misinterpretations.

Thus, the independent between-subject variable is Group, and the dependant withinsubject variable is List, as represented by the performance on the episodic memory task on 
three distinct word lists. Group differences were observed while including IQ as a covariable. To do so, we performed correlations between IQ scores and the average number of words recalled in order to verify the need to include IQ as a covariate. We performed a mixed ANCOVA to compare the three groups (between factor) as a function of the number of words recalled on the three word lists while controlling for IQ. Then, pairwise comparisons corrected for multiple comparisons (Bonferroni, $p=.05 / 3=.017$ ) were used to observe how the three groups specifically differed from each other in their episodic memory performance on the separate word lists.

Finally, we used a multivariate ANOVA to compare the three groups' emotional judgements of arousal level and valence of their respective auditory excerpts in order to validate that the selected auditory stimuli were perceived as intended. The significance level used in each analysis is $p=.05$. Data were analyzed using IBM SPSS Statistics software 23.0 (IBM corporation, 2015).

\section{Results}

A multivariate ANOVA indicated that there were no group differences in the number of correct responses in the distractive mathematical equations (see Table IV). Also, very few participants made errors in the recall of the word lists in the episodic memory task. Consequently, this justifies that the following results concern specifically the effect of auditory backgrounds on the number of words correctly recalled.

\section{Intellectual quotient}

A marginally significant positive correlation exists between global IQ scores and the average number of words recalled ( $r=.34, p=.06$; see Figure 4). Though the correlation is only close to statistical significance, this relation shows that participants who have higher IQ scores tend to recall a greater number of words. This supports the inclusion of IQ as a covariate in the analysis of group differences in the performance of the episodic memory task. 


\section{Episodic memory scores}

The number of words recalled on each list as a function of groups, when IQ is controlled for $(M=116.35)$, is shown in Figure 5. A mixed ANCOVA analysis of Group and List factors was performed while including IQ as a covariate. This analysis revealed a significant interaction of Group and List in the number of words correctly recalled $\left(F_{(4,54)}=\right.$ $\left.2.58, p=.048, \eta^{2}=.16\right)$. The Figure 5 indicates that the interaction occurs on the third list only. In other words, this interaction shows that all three groups performed similarly on the first and second lists, but differently on the third list.

In order to know which groups differed from each other, we performed three univariate ANCOVAs on the third list, which confirm that there is a significant group difference $(F=$

$\left.3.96, p=.031, \eta^{2}=.234\right)$. The stimulant group performed better than the relaxant group $(F=$ $4.52, p=.049)$ and the noise group $(F=5.68, p=.028)$ on the third list, while the later two groups' performances remained stable across trials. However, those differences do not reach the significance level when the analyses are adjusted for multiple comparisons (i.e. adjusted alpha level of $p=.05 / 3=0.017$ ).

The relaxant and noise groups' performances did not differ from each other. Importantly, those differences are far from being significant when IQ is not included as a covariate and the unexplained variance of error becomes much wider. Consequently, although the stimulant group's number of words recalled is only close from being statistically greater than the number of words recalled in both other groups, it appears that IQ plays an important role in producing this tendency. It is possible that the lack of statistical significance is due to a lack of power from the small sample size. Nevertheless, these results support the importance of controlling for IQ.

\section{Emotional judgements}

As you can see in Table V, the stimulant group rated their musical excerpts as being very stimulating, as opposed to the relaxant group who evaluated theirs as being very relaxing. Both stimulant and relaxant groups rated the excerpts as pleasant. Those emotional judgements are concordant with the reasons why we initially selected those musical excerpts. 
Finally, the noise group evaluated the noise as neither arousing nor relaxing and quite unpleasant. The selection of those excerpts permitted to expose groups of participants to stimuli of different arousal levels.

Indeed, a multivariate ANOVA comparing emotional judgements between the three groups revealed significant differences $(p<.001)$. Post-hoc tests indicate that the stimulating background music was more arousing than both the pink noise and the relaxing background music $(p<.001)$, and that the pink noise was more arousing than the relaxing music $(p<$ $.001)$. Also, while the stimulating and relaxing background music are equally pleasant, both stimulating $(p=.006)$ and relaxing $(p=.001)$ excerpts were more pleasant than the pink noise. Generally, musical emotions were perceived and evaluated as intended.

\section{Discussion}

The fact that a majority of university students study in the presence of background music motivated this study to question the actual impact of background music on episodic memory. While some researchers have tried to answer this question before, it remains unclear whether background music actually has the potential to improve such memory performances. One suggestion is that music indirectly influences cognitive performances by modulating the listeners' emotions. In the aim to clarify the effect of background music on episodic memory, we manipulated musical emotions, arousal levels in particular, and included a non-musical auditory stimulus as a control group (noise). We also aimed to control for the influence of IQ. Our main hypothesis was that stimulating background music would benefit episodic memory performances compared to relaxing background music. We also expected the noise group to perform midway between the stimulant and relaxant groups' performances.

Interestingly, our main results indicate that the stimulant group recalled the same number of words as other groups on the first and second lists, but tended to perform better than both the relaxant and the noise groups on the third list. However, this tendency was not observed when we did not control for the effect of IQ. Indeed, we observed that the ability to learn and recall episodic memories is correlated with IQ scores. This means that the number of words recalled may change according to the different levels of IQ, which is concordant with previous research (Alexander \& Smales, 1997; Chamorro-Premuzic \& Furnham, 2007). Thus, 
IQ seems to be an important variable to control for when observing the effect of background music on episodic memory, as shown by the lack of even marginal group differences when we did not consider IQ in our analyses. Importantly, these results show that it is equally important to consider IQ despite that groups seem similar on this variable (e.g. university students). In accordance with our results, a study demonstrated that there was no effect of background music on episodic memory, but that group differences appeared when the effect of IQ was controlled for (Chomorro-Premuzik \& Furnham, 2007). Consequently, the lack of control over individual differences such as IQ could contribute to explain a portion of the previous heterogeneous results.

The fact that the tendency to perform better on the episodic memory task was only seen in the stimulant group compared to the two other groups suggests that the marginally significant interaction is not caused by mere practice. Additionally, the marginal improvement observed in the stimulant group across the first and third lists does suggest a potential role of prolonged exposure to the stimulating music. One possible explanation for our results is provided by the perceptual fluency attribution model (adapted by Jacoby \& Kelley, 1990; Kruglanski, Freund, \& Bar-Tal, 1996). When making an emotional judgement about a stimulus presented for the first time, the affective response is analogous to an hypothesis which is to be validated across repeated exposures. Repeated exposures to the same or to a very similar stimulus therefore result in an increased fluency in processing the characteristics of the presented stimulus. Then, the plausibility of the initially created hypothesis increases, and the resulting emotional judgement of the stimulus becomes stronger after each additional exposure. As a result, attitudes about stimuli tend to polarize upon repeated exposures (Kruglanski, Freund, \& Bar-Tal, 1996; Witvliet \& Vrana, 2007).

This possibility is supported by Eich and Metcalfe (1989) who demonstrated that the perceived arousal level of emotionally-similar musical excerpts increases over repeated exposures. In other words, arousal was evaluated as significantly higher and higher across additional exposures to equally stimulating musical excerpts. Moreover, Carr and Rickard (2016) specified that this effect occurred with stimulating and pleasant music, while such polarization was not observed in stimuli which conveyed neither positive nor negative emotions. 
Interestingly, our results showed that the number of words recalled by the stimulant group gradually increased from the first to the third list. Moreover, this trend was only seen in the pleasant and arousing music group. If Eich and Metcalfe's (1989) suggestion holds in the context of our study, then this could provide some partial support for the mood arousal theory considering that prolonged exposure may be key to its effect. Importantly, previous research suggested that a single exposure to a musical excerpt may not be sufficient to induce a particular mood in the listener (Eich \& Metcalfe, 1989). In other words, an elevated arousal and a positive mood may indeed benefit cognitive performances, but this effect may require prolonged exposures to similarly arousing and pleasant stimuli.

\section{Strengths}

The strengths of this study include the use of a non-musical auditory group, which allowed us to examine whether background music impacts episodic memory differently compared to other auditory stimulation. Moreover, the control noise was adapted to the selected musical excerpts which increases its accuracy as a control noise. We also selected our musical excerpts more objectively compared to the methods used in previous research. Indeed, asking participants to evaluate several musical excerpts on their arousal level and emotional valence in a pre-study helped us to select musical excerpts that corresponded to the targeted emotional characteristics, as confirmed by our participants.

Another strength is the control with which we created the episodic memory task. Indeed, the nature of the words that compose a memory task can strongly influence our ability to memorize them. For example, emotional words or words of higher frequency of use seem to be more readily recalled (Balota \& Neely, 1980; Hicks, Marsh, \& Cook, 2005). As such, it is important to minimize the difficulty differences between the word lists by considering such influencing variables. This has been done by selecting words of equal frequency of use, concreteness, imageability, emotional valence, and length. As highlighted in the general Discussion section, we think that this method was efficient due to the fact that there were no list effect, and that in the exception of the stimulant group who performed marginally better on the third list only, the relaxant and noise groups' performances remained stable across all three trials. Thus, we are confident that the lists were indeed of a similar difficulty level. 


\section{Limitations and future research}

Acknowledging the possibility that the perceived arousal levels of stimulating music may change from the first to the third exposures to the music, it is regretful that emotional judgements were only taken when the excerpts were replayed after the end of the task rather than immediately after having heard the auditory excerpts during the memory task. Given that these emotional judgements may change over time, it is possible that those obtained from this method are not exactly representative of the emotional judgements that would have been obtained from measuring them after each exposure during the memory task. Clearer influences of exposure on perceived arousal levels could be provided with immediate evaluations of the stimuli, at each additional trial.

Also, the lack of measurement of emotional changes during the task progression does not allow us to observe whether emotion induction truly occurred, and if so, at which moment during the course of the experiment. Indeed, though visual analogue scales' ratings support that the musical emotions were perceived as intended, this does not ensure that these emotions were experienced internally.

Moreover, the small group sizes may have diminished the power of the statistical tests. This limit also appears in the important between-group variance in the number of words recalled on the first and second list, which strongly overlap. It is possible that clearer results would emerge if the group sizes were increased.

Despite those limitations, this study demonstrates that future research should pay closer attention to individual differences. Namely, this study supports that IQ is an important factor to control for in order to reduce the between-group variance and increase the probability of finding significant results. Moreover, it will be important to consider the use of mixed or between-subjects designs in the future, especially regarding the Group factor. Doing so could help researchers to clarify the hypothesis that stimulating background music may benefit episodic memory upon repeated exposures to stimulating musical excerpts. Indeed, previous studies using an entirely within-subject design could have failed to capture the potential effect of a prolonged exposure to particular musical emotions because musical emotions inevitably 
change often in this type of design and this short amount of time may not be sufficient to alter the listener's moods (Eich \& Metcalfe, 1989).

Ideally, future research should also observe the time course of physiological responses to such repeated exposures. Doing so would allow to observe changes in emotional states at specific time points. This would help to track more precisely whether repeated exposures lead to emotional changes as well as when these changes precisely occur, and how that impacts on episodic memory.

\section{Implications}

Despite these limitations and the limited amount of information on the topic, our findings open up important prospects for the current field of study. Indeed, our results demonstrate that it is possible that various musical characteristics benefit episodic memory in different ways. Namely, they suggest that the pleasantness of background music is not sufficient to explain its potential beneficial effect on episodic memory, as shown by the lack of group differences in groups who listened to equally pleasant musical excerpts. As such, students' perception that pleasant background music helps their memory performances remain questionable. However, this study may suggest partial support for the mood arousal theory, which seemed to be conditional to prolonged musical exposure in the current study. Clarifying the possible contribution of musically-induced arousal on episodic memory could in turn have important implications. Namely, understanding the role of musically-induced changes in arousal levels on episodic memory could help to optimize the use of music in the context of learning, including in educational settings. Research in this area is particularly relevant in academic programs which prompt background music listening during classwork (White, 2007; Tuazon, 2015). Indeed, while listeners' perceptions may lead to the belief that music has some beneficial effects, it does not seem entirely congruent with our current knowledge of the domain. Moreover, background music listening in academic contexts must be used conscientiously due to the very complex nature of its influence on episodic memory as well as on cognitive performances in general. Additionally, it is important to note that the use of background music during the cognitive performances of a group of individuals (e.g. classrooms) may have diverse effects according to individual differences (e.g. IQ), which has 
been little studied in this context. This possibility must be observed carefully given the integrative nature of today's classrooms which may include students with lower than average IQ. 


\section{Bibliography}

Alexander, J., \& Smales, S. (1997). Intelligence, learning and long-term memory. Personality and Individual Differences, 23 (5), 815-825.

Alley, T. R., \& Greene, M. (2008). The relative and perceived impact of irrelevant speech, vocal music and non-vocal music on working memory. Current Psychology, 27, 277-289.

Atkinson, R. C., \& Shiffrin, R. M. (1971). The control processes of short-term memory. Institute for Mathematical Studies in the Social Sciences, Stanford University.

Bachem, A. (1955). Absolute pitch. Journal of the Acoustical Society of America, 27, 11801185.

Baddeley, A. D. (1975). Word-length and the structure of short-term memory. Journal of Verbal Learning and Verbal Behavior, 14 (6), 575-589.

Baddeley, A. D., \& Scott, D. (1971). Word frequency and the unit-sequence interference hypothesis in short-term memory. Journal of Verbal Learning and Verbal Behavior, $10,35-40$.

Bahrick, H. P., Bahrick, P. O., \& Wittinger, R. P. (1975). Fifty years of memory for names and faces: a cross-sectional approach. Journal of Experimental Psychology: General, 104, 54-75.

Balota, D. A., \& Neely, J. H. (1980). Test-expectancy and word-frequency effects in recall and recognition. Journal of Experimental Psychology: Human Learning \& Memory, 6 (5), 576-587.

Beauchemin, N., Martel, P., Théoret, M. (1992). Dictionnaire de fréquence des mots du Français parlé au Québec: Fréquence, dispersion, usage, écart réduit. Peter Lang Inc., International Academic Publisher, 1st edition.

Behne, K. E. (1999). Zu einer theorie der wirkungslosigkeit von hintergrund musik. On a theory of the non-impact of background music. Musik psychologie: Jarhbuch der Deutschen Gesellschaft für Musik Psychologie, 14, 7-23.

Bigand, E., Barabara, T., Peretz, I., Zatorre, R. J., Lopez, L., \& Majno, M. (2015). Musical 
pleasure and reward: Mechanisms and dysfunction. Annals of the New York Academy of Sciences, 1337 (1), 202.

Blood, A. J., Zatorre, R. J., Bermudez, P., \& Evans, A. C. (1999). Emotional responses to pleasant and unpleasant music correlate with activity in paralimbic brain regions. Nature Neuroscience, 2.

Blood, A. J., \& Zatorre, R. J. (2001). Intensely pleasurable responses to music correlate with activity in brain regions implicated in reward and emotion. Proceedings of the National Academy of Sciences, USA, 98 (20).

Boman, E., Enmarker, I., and Hygge, S. (2005). Strength of noise effects on memory as a function of noise source and age. Noise Health 7, 11-26.

Bonin, P., Méot, A., Aubert, L., Malardier, N., Niedenthal, P., \& Capelle-Toczek, M-C. (2003). Normes de concrétude, de valeur d'imagerie, de fréquence subjective et de valence émotionnelle pour 866 mots. L'année psychologique, 103 (4), 655-694.

Bottiroli, S., Rosi, A., Russo, R., Vecchi, T., \& Cavallini, E. (2014). The cognitive effects of listening to background music on older adults: processing speed improves with upbeat music, while memory seems to benefit from both upbeat and downbeat music. Frontiers in Aging Neuroscience, 6 (284)

Brierley, B., Medford, N., Shaw, P., \& David, A. S. (2007). Emotional memory for words: Separating content and context. Cognition and Emotion, 21 (3), 495-521.

Calderwood, C., Ackerman, P. L., \& Conklin, E. M. (2014). What else do college students "do" while studying? An investigation of multitasking. Computers \& Education, 75, 19-29.

Carr, S. M., \& Rickard, N. (2016). The use of emotionally arousing music to enhance memory for subsequently presented images. Psychology of Music, 44 (5).

Cassidy, G., \& Macdonald, R. A. R. (2007). The effect of background music and background noise on the task performance of introverts and extraverts. Psychology of Music, 35 (3), 517-537.

Chabris, C. F. (1999). Prelude or requiem for the 'Mozart effect'? Nature, 400, 826-827.

Chamorro-Premuzik, T., \& Furnham, A. (2007). Personality and music: Can traits explain how people use music in everyday life? British Journal of Psychology, 98, 175-185. 
Choi, J. H. (2003). The relationships among characteristic moods, music preference, and music listening habits: A survey study. Michigan State University, ProQuest Dissertations Publishing.

Clément, F., Belleville, S., \& Mellah, S. (2009). Functional neuroanatomy of the encoding and retrieval processes of verbal episodic memory in MCI. Cortex, 46, 1005-1015.

Cohen, N. J., \& Squire, L. R. (1980). Preserved learning and retention of pattern analyzing skill in amnesia: Dissociation of knowing how and knowing that. Science, 210, 207209.

Danna Bella, S., Peretz, I., Rousseau, L., \& Gosselin, N. (2001). A developmental study of the affective value of tempo and mode in music. Cognition, 80, 1-10.

De Groot, A. M. B. (2006). Effects of stimulus characteristics and background music on foreign language vocabulary learning and forgetting. A Journal of Research in Language Studies, 56 (3), 463-506.

DeLosh, E. L., \& McDaniel, M. A. (1996). The role of order information in free recall: Application to the word-frequency effect. Journal of Experimental Psychology: Learning, Memory, and Cognition, 22 (5), 1136-1146.

Desrochers \& Bergeron (2000). Valeurs de fréquence subjective et d'imagerie pour un échantillon de 1916 substantifs de la langue Française. Canadian Journal of Experimental Psychology, 54 (4), 288.

Digiacomo. A., \& Kirby, B. (2006). The effect of musical mode on emotional state/ L'effet du mode musical sur l'état émotionnel. Canadian Journal of Music Therapy, 12 (1), 6890.

Dickerson, B. C., \& Eichenbaum, H. (2010). The episodic memory system : Neurocircuitry and disorders. Neuropsychopharmacology, 35 (1), 86-104.

Doerkson, S., \& Shimamura, P. (2001). Source memory enhancement for emotional words. Emotion, 1 (1), 5-11.

Eich, E., \& Metcalfe, J. (1989). Mood dependant memory for internal versus external events. Journal of Experimental Psychology, Learning, Memory and Cognition, 15 (3), 443-455.

Erk, S., Kiefer, M., Grothe, J., Wunderlich, A. P., Spitzer, M., \& Walter, H. (2003). Emotional context modulates subsequent memory effect. NeuroImage, 18, 439-447. 
Fernandes, M. A., Wammes, J. D., Priselac, S., \& Moscovitch, M. (2016). Interfering with free recall of words: Detrimental effects of phonological competition. Neuropsychologia.

Fernandez-Sotos, Fernandez-Caballero, \& Latorre, J. (2016). Influence of tempo and rhythmic unit in musical emotion regulation. Frontiers in Computational Neuroscience, 3 (10).

Ferreri, L., Aucouturier, J-J., Muthalib, M., Bigand E., \& Bugaiska, A. (2013). Music improves verbal memory encoding while decreasing pre-frontal cortex activity: an fNIRS study. Frontiers in Human Neuroscience, 7 (779).

Ferreri, L., Bigand, E., Bard, P., \& Bugaiska, A. (2015). The influence of music on prefrontal cortex during episodic encoding and retrieval of verbal information: A Multichannel fNIRS Study. Behavioral Neurology.

Ferreri, L., Bigand, E., \& Bugaiska, A. (2015). The positive effect of music on source memory. Musicae Scientiae, 19 (4).

Ferreri, L., Bigand, E., Perrey, S., Muthalib, Bard, P., \& Bugaiska, A. (2014). Less effort, better results: How does music act on pre-frontal cortex in older adults during verbal encoding? An fNIRS study. Frontiers in Human Neuroscience, 8 (301), 1-11.

Ferreri, L., Mas-Herrero, E., Zatorre, R. J., Marco-Pallarés, J., Gomez-Andrés, A., Alicart, H., Olivié, G., Valle, M., Antonijan, R., Riba, J., \& Rodriguez-Fornells, A. (2017). Musicrelated reward responses modulate episodic memory formation via the hippocampusdependent dopaminergic circuit. Poster presentation: The Neurosciences and Music VI, Music, Sound and Health.

Ford, J. H., Morris, J. A., \& Kensinger, E. A. (2014). Effects of emotion and emotional valence on the neural correlates of episodic memory search and elaboration. Journal of Cognitive Neuroscience, 26 (4), 825-839.

Furnham, A., \& Allass, K. (1999). The influence of musical distraction of varying complexity on the cognitive performance of extraverts and introverts. European Journal of Personality, 13, 27-38.

Furnham, A., \& Braddley, A. (1997). Music while you work: The differential distraction of background music on the cognitive test performance of introverts and extraverts. Applied Cognitive Psychology, 11, 445-455.

Gabrielsson, A., \& Lindstrom, S. (2003). Strong experiences related to music: A descriptive system. Musicae Scientiae, 7 (2), 157-217. 
Greasley, A. E., \& Lamont, A. (2009). Exploring engagement with music in everyday life using experience sampling methodology. European Society for the Cognitive Sciences of Music.

Greasley, A. E., \& Lamont, A. (2011). Exploring engagement with music in everyday life using experience sampling methodology. Musicae Scientiae, 15 (1), 45-71.

Gomez, P., Danuser, B., \& Phelps, E. A. (2007). Relationships between musical structure and psychophysiological measures of emotion. Emotion, 7 (2), 377-387.

Gosselin, N., Paquette, S., \& Peretz, I. (2015). Sensitivity to musical emotions in congenital amusia. Cortex, 71, 171-182.

Guhn, M., Hamm, A., \& Zentner, M. (2007). Physiological and musico-acoustic correlates of the chill response. Music Perception: An Interdisciplinary Journal, 25 (5), 473-484.

Hargreaves D. J., North A. C. (1999). The functions of music in everyday life: redefining the social in music psychology. Psychology of Music, 27, 71-83.

Hasselmo, M. E. (2012). How we remember: Brain mechanisms of episodic memory. Chapter 1: Behavioral dynamics of episodic memory. MIT Press, 366 pages.

Hebert, D. M. B., \& Burt, J. S. (2003). The effects of different review opportunities on schematization of knowledge. Learning and Instruction, 13, 73-92.

Hicks, J. L., Marsh, R. L., \& Cook, G. I. (2005). An observation on the role of context variability in free recall. Journal of Experimental Psychology: Learning, Memory, and Cognition, 31 (5), 1160-1164.

Husain, G., Thompson, W. F., \& Schellenberg, G. (2002). Effects of musical tempo and mode on arousal, mood, and spatial abilities. Music Perception, 20 (2), 151-171.

Hygge, S., Boman, E., and Enmarker, I. (2003). The effects of road traffic noise and meaningful irrelevant speech on different memory systems. Scandinavian Journal of Psychology, 44, 13-21.

IBM Corporation (2015). IBM SPSS Statistics for Windows, Version 23.0. IBM corp. Armonk, NY, USA.

Ilie, G., \& Thompson, W. F. (2006). A comparison of acoustic cues in music and speech for three dimensions of affect. Music Perception, 23 (4), 319-329.

Iwanaga, M., \& Morok, Y. (1999). Subjective and physiological responses to music stimuli 
controlled over activity and preference. Journal of Music Therapy, 36 (1), 26-38.

Jacoby, L. L., \& Kelley, C. M. (1990). An episodic view of motivation: Unconscious Influences on memory. The handbook of motivation and cognition, 2, 451-581.

Jäncke, L., Brügger, E., Brummer, M., Scherrer, S., \& Alahmadi, N. (2014). Verbal learning in the context of background music: no influence of vocals and instrumentals on verbal learning. Behavioral and Brain Functions, 10 (10).

Jäncke, L., \& Sandmann, P. (2010). Music listening while you learn: No influence of background music on verbal learning. Behavioral and Brain Functions, 6 (3).

Judde, S., \& Rickard, N. (2010). The effect of post-learning presentation of music on long-term word list retention. Neurobiology of Learning and Memory, 94, 13-20.

Juslin, P. N., \& Sloboda, J. (2001). Handbook of music and emotion: Theory, research, applications. New York: Oxford University Press.

Juslin, P. N., \& Västfjäll, D. (2008). Emotional responses to music: The need to consider underlying mechanisms. Behavioral and Brain Sciences, 31, 559-575.

Kampfe, J., Sedlmeier, P., \& Renkewitz, F. (2010). The impact of background music on listeners: A meta-analysis. Psychology of Music, 39 (4), 424-448.

Kensinger, E. A., \& Corkin, S. (2003). Memory enhancement for emotional words: Are emotional words more vividly remembered than neutral words? Memory and Cognition, 31 (8), 1169-1180.

Keppel, G., \& Underwood, B. J. (1962). Proactive inhibition in short-term retention of single items. Journal of Verbal Learning and Verbal Behavior, 1, 153-161.

Kintsch, W. (1970). Models for free recall and recognition. Models of Human Memory, New York: Academic Press.

Kruglanski, A. W., Freund, T., \& Bar-Tal, D. (1996). Motivational effects in the mereexposure paradigm. European Journal of Social Psychology, 26, 479-499.

Labbé, E., Schmidt, N., Babin, J., \& Pharr, M. (2007). Coping with stress: The effectiveness of different types of music. Applied Psychophysiology and Biofeedback, 32 (3), 163168.

Leveque, Y., Tillman, B., \& Caclin, A. (2015). Musical emotions in amusia: dissociation between emotion recognition and intensity judgements. Bi-annual conference of the international society for research on emotion. 
Lonsdale, A. J., \& North, A. C. (2011). Why do we listen to music? A uses and gratifications analysis. British Journal of Psychology, 102, 108-134.

Lundqvist, L. O., Carlsson, F., Hilmersson, P., \& Juslin, N. (2008). Emotional responses to music: Experience, expression, and physiology. Society for Education, Music and Psychology Research, 37 (1).

Mahdavi, M. E., \& Peyvandi, A. A. (2007). Accuracy of cortical evoked response audiometry in estimating normal hearing thresholds. Tehran University Medical Journal, 65 (3), $17-22$.

Martinez-Molina, N., Mas-Herrero, E., Rodriguez-Fornells, A., Zatorre, R. J., Marco-Palléres, J. (2016). Neural correlates of specific musical anhedonia. Proceedings of the National Academy of Sciences of the United States of America, 113 (46).

Mas-Herrero, E., Pallarés, J. M., Lorenzo-Seva, U., Zatorre, R. J., \& Rodriguez-Fornells, A. (2013). Individual differences in music reward experiences. Music Perception: An Interdisciplinary Journal, 31 (2), 118-138.

Nantais, K. M., \& Schellenberg, E. G. (1999). The Mozart effect: An artifact of preference. Psychological Science, 10 (4), 370-373.

North, A.C., Hargreaves, D.J. \& Hargreaves, J.J. (2004). Uses of music in everyday life. Music Perception, 22 (10), 41-77.

Perner J, Ruffman T. 1995. Episodic memory and autonoetic consciousness: Developmental evidence and a theory of childhood amnesia. Journal of Experimental Child Psychology 59, 516-548.

Peretz, I., Ayotte, J., Zatorre, R. J., Mehler, J., Ahad, P., Penhune, V. B., \& Jutra, B. (2002). Congenital amusia: A disorder of fine grained pitch discrimination. Neuron, 33 (2), 185-191.

Peretz, I., Gosselin, N., Tillmann, B., Cuddy, L. L., Gagnon, B., Trimmer, C. G., Paquette, S., \& Bouchard, B. (2008). Online identification of congetinal amusia. Music Perception, $25(4), 331-343$.

Peterson, D. J., \& Mulligzn, N. W. (2012). A negative effect of repetition in episodic memory. Journal of Experimental Psychology: Learning, Memory and Cognition, 38 (6), 17861791.

Peterson, Lloyd; Peterson, Margaret Jean (September 1959). "Short-term retention of 
individual verbal items". Journal of Experimental Psychology, 58 (3), 193-198.

Posner, M. I. (1966). "Components of skilled performance". Science, 152 (3730), 1712-1718.

Postman, L., \& Keppel, G. (1977). Conditions of cumulative proactive inhibition. Journal of Experimental Psychology: General, 106, 376-403.

Proverbio, A. M., Nasi, V. L., Arcari, L. A., De Benedetto, F., Guardamagna, M., Gazzola, M., \& Zani, A. (2015). The effect of background music on episodic memory and autonomic responses: listening to emotionally touching music enhances facial memory capacity. Scientific Reports, 5 (15219), 1-12.

Psychology Software Tools, Inc. E-Prime 2.0. (2012). Retrieved from http://pstnet.com.

Rauscher, F. H., Shaw, G. L., \& Ky, K. N. (1993). Music and spatial task performance. Nature, 365 (6447), 611.

Rickard, N. (2004). Intense emotional responses to music: A test of the physiological arousal hypothesis. Psychology of Music, 32 (4), 371-388.

Russo, F. A., Vempala, N. N., \& Sandstrom, G. M. (2013). Predicting musically induced emotions from physiological inputs: linear and neural network models. Frontiers in Psychology, 4 (468).

Salamé, P., \& Baddeley, A. D. (1982). Disruption of short-term memory by unattended speech: Implications for the structure of working memory. Journal of Verbal Learning and Verbal Behavior, 21, 150-164.

Saliba, J., Lorenzo-Seva, U., Marco-Pallares, J., Tillmann, B., Zeitouni, A., \& Lehmann, A. (2016). French validation of the Barcelona music reward questionnaire. Peerj, 4.

Schäfer T., Sedlmeier P. (2009). From the functions of music to music preference. Psychology of Music, 37, 279-300.

Schellenberg, E. G., Nakata, T., Hunter, P. G., \& Tamoto, S. (2007). Exposure to music and cognitive performance: Tests of children and adults. Society for Education, Music and Psychology Research, 35 (1), 5-19.

Schwabe, L., \& Wolf, O. T. (2010). Learning under stress impairs memory formation. Neurobiology of Learning and Memory, 93 (2), 183-188.

Skarlatos, D., \& Georgiou, A. (2001). Memorization of young people under loud pink noise of short duration. Perceptual and Motor Skills, 92, 89-94.

Söderlund, G. B. W., Sikström, S., Loftesnes, J. M., \& Sonuga-Barke, J. (2010). The effects of 
background white noise on memory performance in inattentive school children. Behavioral and Brain Functions, 6 (55).

Söderlund, G. B. W., Sikström, S., and Smart, A. (2007). Listen to the noise: noise is beneficial for cognitive performance in ADHD. Journal of Child Psychology: Psychiatry, 48, 840-847.

Souchay, C., Guillery-Girard, B., Pauly-Takacs, K., Wojcik, D. Z., \& Eustache, F. (2013). Subjective experience of episodic memory and metacognition: A neurodevelopmental approach. Frontiers in Behavioral Neuroscience, 7 (212).

Squire, L. R. (2004). Memory systems of the brain: A brief history and current perspective. Neurobiology of Learning and Memory, 82 (171-7).

Squire, L. R., \& Zola-Morgan, M. (1991). The medial temporal lobe memory system. Science, 253, 1380-1386.

Straehley, I. C., \& Loebach, J. L. (2014). The influence of mode and musical experience on the attribution of emotions to melodic sequences. Psychomusicology: Music Mind and Brain, 24 (1), 21-34.

Stratton, V. N., \& Zalanowski, A. H. (2003). Daily music listening habits in college students: Related moods and activities. Psychology and Education: An Interdisciplinary Journal, 40, 1-11.

Suda, M., Morimoto, K., Obata, A., Koizumi, H., \& Maki, A. (2008). Emotional responses to music: Towards scientific perspectives on music therapy. Neuroreport, 19 (1), 75-78.

Surprenant, A. M. (1999). The effect of noise on memory for spoken syllables. Journal of Psychology, 34 (5-6), 328-333.

Surprenant, A. M., \& Neath, L. (1996). The relation between discriminability and memory for vowels, consonants, and silent-center vowels. Memory and Cognition, 24, 356-366.

Szalma, J. L., \& Hancock, P. A. (2011). Noise effects on human performance: a meta-analytic synthesis. Psychology Bulletin, 137 (4), 682-707.

Tat, D., Pelletier, G., Massicotte, E., \& Gosselin, N. (2015). The Relation between Perceived Physiological Arousal and Valence during Relaxing Music Listening. Poster presentation: Journée scientifique de l'Université de Montréal.

Tesoriero, M., \& Rickard, N. S. (2012). Music-enhanced recall: An effect of mood 
congruence, emotion arousal, or emotion function? Musicae Scientiae, 16 (3), 340-356.

Thompson, W. F., Schellenberg, E. G., \& Husain, G. (2001). Arousal, Mood and the

Mozart effect. Psychological Science, 12 (3).

Tuazon, A. (2015). Integrating music in the elementary classroom. Thesis from the University of Toronto.

Tulving, E. (1972). Episodic and semantic memory. In E. Tulving \& W. Donaldson (Eds.), Organization of Memory, (pp. 381-403). New York: Academic Press.

Tulving, E. (1985). Memory and consciousness. Canadian Psychology, 26, 1-12.

Tulving, E. (1993). What is episodic memory? Current Directions in Psychological Science, 2 (3), 67-70.

Underwood, B. J. (1957). Interference and forgetting. Psychological Review, 64, 49-60.

Van Der Zwaag, M. D., Westerink, J. H. D. M., \& Van Den Broek, E. L. (2011).

Emotional and psychophysiological responses to tempo, mode, and percussiveness. Musicae Scientiae, 15 (2).

Van Dyck, E., Six, J., \& Leman, M. (2016). The relaxing effect of tempo on music-aroused heart rate. Conference paper, San Fransisco, USA.

Vieillard, S., Peretz, I., Gosselin, N., Khalfa, S., Gagnon, L., \& Bouchard, B. (2008). Happy, sad, scary and peaceful musical excerpts for research on emotions. Cognition and Emotion, 22 (4), 720-752.

Ward, G., Woodward, G., Stevens, A., \& Stinson, C. (2003). Using overt rehearsals to explain word frequency effects in free recall. Journal of Experimental Psychology: Learning, Memory, and Cognition, 29 (2), 186-210.

Wang, Z., \& Tchernev, J. M. (2012). The myth of media multitasking: Reciprocal dynamics of media multitasking, personal needs and gratifications. Journal of Communication, 62, 493-513.

Wang, W-C. (2014). A study of the type and characteristics of relaxing music for college students. The Journal of the Acoustical Society of America, 135 (2185).

Watson D., \& Mandryk, R. L. (2012). An in-situ study of real-life listening context. International Society for Music Information.

Wechsler, D. (1999). Wechsler abbreviated scale of intelligence. San Antonio, TX: The Psychological Corporation. 
Whiffen, J. W., \& Karpicke, J. D. (2017). The role of episodic context in retrieval practice effects. Journal of Experimental Psychology: Learning, Memory and Cognition, 43 (7), 1036-1046.

White, K. N. (2007). The effect of background music in the classroom on the productivity, motivation and behavior of fourth grade students. Columbia College Press.

Witvliet, C. V. O., \& Vrana, S. R. (2007). Play it again Sam: Repeated exposure to emotionally evocative music polarizes liking and smiling responses and influences other affective reports, facial EMG, and heart rate. Cognition and Emotion, 21 (1), 327.

Woloszin, M. R., \& Ewert, L. (2012). Memory for facial expression is influenced by the background music playing during study. Advanced Cognitive Psychology, 8 (3), 226233.

Zatorre, R. J. (2015). Musical pleasure and reward: mechanisms and dysfunction. Annals of the New York Academy of Sciences, 1337, 202-211.

Zwaag, V. (2011). Emotional and psychophysiological responses to tempo, mode and percussiveness. Musicae Scientiae, 15 (2), 250-269. 


\section{Tables and figures}


Table I. Characteristics of participants as a function of groups.

\begin{tabular}{cccc}
\hline & Stimulant & Relaxant & Noise \\
\hline Sex (F/M) & $7 / 3$ & $4 / 5$ & $9 / 2^{*}$ \\
Age & $25.70(3.30)$ & $22.56(2.88)$ & $22.55(3.56)$ \\
Schooling (years) & $17.33(2.35)$ & $16.33(1.94)$ & $16.30(1.83)$ \\
Musical education & $1.06(1.47)$ & $1.20(1.03)$ & $1.93(1.54)$ \\
(years) & & & \\
Background & $8.78(12.43)$ & $8.70(12.18)$ & $4.86(5.86)$ \\
music listening & & & \\
(hours/week) & & & \\
Intellectual & $115.2(9.93)$ & $115.6(11.74)$ & $118.09(9.59)$ \\
quotient & & & \\
\hline
\end{tabular}

Note. None of the group differences are statistically significant (as analyzed using ANOVA with a significance level of $p=.05$ ) in the exception that there are significantly more females than males in the noise group (as analyzed using a khi-squared analysis; $p=.011$ ). Musical experience is reported in terms of the number of years of regular practice of a musical instrument or voice. The numbers in parentheses represent the standard deviations. 
Table II. Description of the musical selection.

\begin{tabular}{|c|c|c|c|c|c|c|c|}
\hline & \multicolumn{3}{|c|}{ Stimulating musical excerpts } & \multicolumn{3}{|c|}{ Relaxing musical excerpts } & \multirow[b]{2}{*}{$\begin{array}{c}\text { Significance } \\
\text { level }\end{array}$} \\
\hline Title & $\begin{array}{l}\text { Dance of } \\
\text { the hours }\end{array}$ & $\begin{array}{c}\text { William } \\
\text { tell } \\
\text { overture } \\
\text { Final }\end{array}$ & $\begin{array}{l}\text { Russian } \\
\text { dance }\end{array}$ & Meditation & $\begin{array}{l}\text { Aria } \\
\text { da } \\
\text { capo }\end{array}$ & $\begin{array}{c}\text { Carmen } \\
\text { suite no. } 1 \\
\text { intermezzo }\end{array}$ & \\
\hline Compositor & Ponchielli & Rossini & Tchaikovsky & Massenet & Bach & Bizet & $\mathrm{N} / \mathrm{A}$ \\
\hline $\begin{array}{c}\text { Arousal } \\
\text { Mean (SD) }\end{array}$ & $\begin{array}{l}94.70 \\
(4.81)\end{array}$ & $\begin{array}{c}88.80 \\
(10.02)\end{array}$ & $\begin{array}{c}87.70 \\
(10.62)\end{array}$ & $\begin{array}{l}10.30 \\
(7.85)\end{array}$ & $\begin{array}{c}12.60 \\
(11.02)\end{array}$ & $\begin{array}{l}18.80 \\
(7.61)\end{array}$ & $p<.001$ \\
\hline $\begin{array}{c}\text { Valence } \\
\text { Mean (SD) }\end{array}$ & $\begin{array}{c}18.40 \\
(16.28)\end{array}$ & $\begin{array}{c}21.50 \\
(17.24)\end{array}$ & $\begin{array}{l}21.10 \\
(21.93)\end{array}$ & $\begin{array}{c}19.30 \\
(21.62)\end{array}$ & $\begin{array}{c}21.90 \\
(14.22)\end{array}$ & $\begin{array}{c}22.30 \\
(15.06)\end{array}$ & ns \\
\hline $\begin{array}{l}\text { Tempo } \\
\text { (bpm) }\end{array}$ & 160 & 153 & 145 & 96 & 72 & 64 & $p=.005$ \\
\hline $\begin{array}{l}\text { Temporal } \\
\text { selection } \\
\text { (seconds) }\end{array}$ & $\begin{array}{l}508 \mathrm{~s} . \text { to } \\
583 \mathrm{~s} \text {. }\end{array}$ & $\begin{array}{l}15 \mathrm{~s} . \text { to } \\
90 \mathrm{s.}\end{array}$ & 2 s. to $77 \mathrm{~s}$. & $\begin{array}{c}4 \text { s. to } 79 \\
\text { s. }\end{array}$ & $\begin{array}{l}1 \mathrm{~s} . \text { to } \\
76 \mathrm{~s} .\end{array}$ & $\begin{array}{l}1 \text { s. to } 76 \\
\text { s. }\end{array}$ & N/A \\
\hline
\end{tabular}

Note. The temporal selection represents the beginning and the ending interval of each musical excerpt, based on the original musical piece. The stimulating musical excerpts are significantly more arousing and faster than the relaxing musical excerpts as observed by comparing their mean arousal ratings and beats per minute with t-tests. 
Table III. Comparison of the three word lists on the words' selection criteria

\begin{tabular}{cccc}
\hline & List 1 & List 2 & List 3 \\
\hline Frequency of use & $30.40(22.91)$ & $29.73(25.72)$ & $29.20(18.46)$ \\
Concreteness & $4.76(0.10)$ & $4.73(0.12)$ & $4.85(0.54)$ \\
Imageability -7 & $6.64(0.17)$ & $6.64(0.12)$ & $6.67(0.14)$ \\
Valence & $3.10(0.55)$ & $3.08(0.47)$ & $3.23(0.71)$ \\
Syllables & $2.27(0.46)$ & $2.27(0.46)$ & $2.2(0.41)$ \\
\hline
\end{tabular}

Note. Concreteness: 1 = abstract, $5=$ concrete; Frequency of use: occurrences per million words; Imageability - 7: $1=$ non-imaginable, $7=$ easily imaginable; Valence: $1=$ very unpleasant, $5=$ very pleasant.

The numbers represent the mean ratings on each criterion and standard deviations appear in parentheses. None of the lists are significantly different according to these criteria $(p<.05)$. 
Table IV. Average number of correct answers in the three series of mathematical equations as a function of group.

\begin{tabular}{llll}
\hline & $1^{\text {st }}$ series & $2^{\text {nd }}$ series & $3^{\text {rd }}$ series \\
\hline Stimulant group & $48.00(17.54)$ & $57.30(25.24)$ & $55.80(22.52)$ \\
Relaxant group & $57.40(16.67)$ & $62.20(19.21)$ & $59.30(19.82)$ \\
Noise group & $63.09(23.00)$ & $68.00(24.73)$ & $57.94(20.29)$ \\
\hline
\end{tabular}

Note. None of the results are statistically different, as analyzed in a mixed ANOVA at a significance level of $p=.05$. 
Table V. Average emotional judgements of the musical excerpts in each group.

\begin{tabular}{lll}
\hline & Arousal & Valence \\
\hline Stimulating music & $86.81(8.53) *$ & $71.67(24.59)$ \\
Relaxing music & $10.04(9.35)^{*}$ & $82.83(17.74)$ \\
Noise & $48.44(20.92)^{*}$ & $35.07(23.37)^{*}$ \\
\hline
\end{tabular}

Note. Those evaluations were made using the visual analogue scales. Each auditory context was evaluated as being significantly different from each other in terms of arousal level according to a multivariate ANOVA. However, the noise was evaluated as being less pleasant than the stimulating and relaxing musical excerpts. These numbers represent the mean ratings of the auditory excerpts and standard deviations are shown in parentheses. Asterisks $\left(^{*}\right)$ represent a significant difference of $p<.001$. 
Figure 1. Tulving's model of memory (1993). According to this model, our variable of interest (i.e. episodic memory) is classified as declarative (explicit) long-term memory. EM includes the memory for specific events such as times, places, contexts and associated emotions and is differentiated from semantic memory which concerns general knowledge and meaning of the external world. The illustration was retrieved from Squire (1991, 2004).

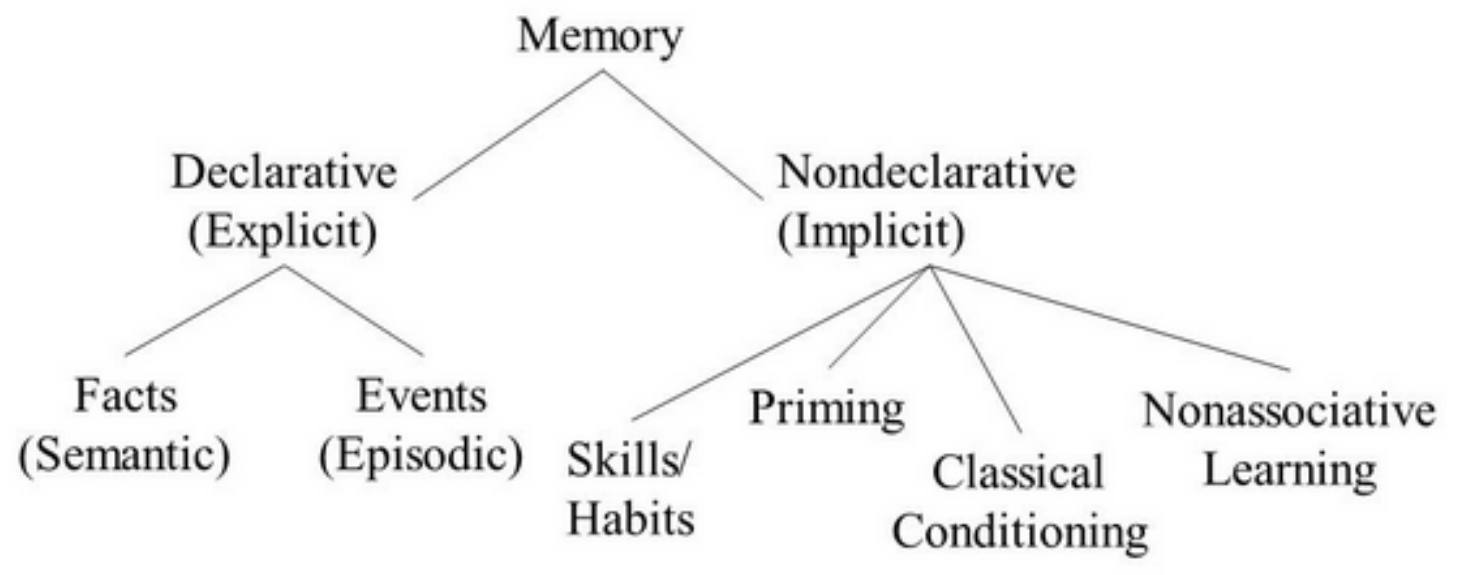


Figure 2. Phases of the episodic memory task as a function of time. This figure describes the three phases of the episodic memory task (word lists). The auditory stimulus (stimulating or relaxing background music, pink noise) assigned to the participant is presented in the encoding phase only and is represented by the darkened area. This procedure is repeated for the three word lists.

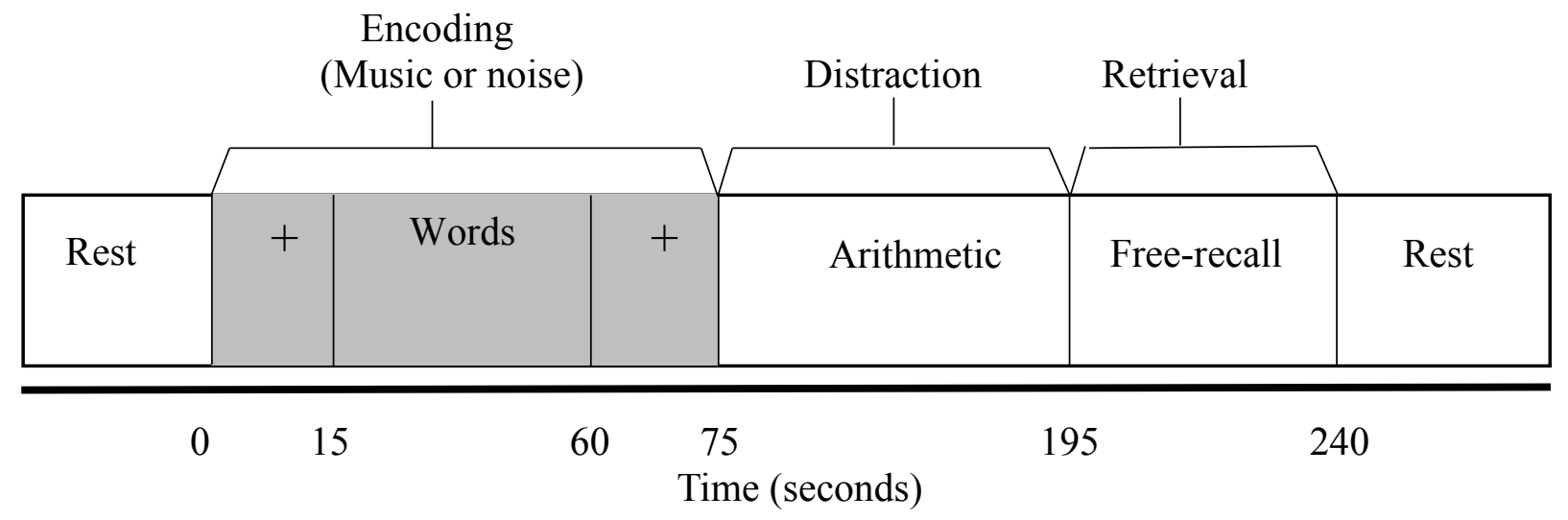


Figure 3. Visual analogue scales. On each computerized visual analogue scale, participants are asked to click on the line at the point which represents best their feelings towards their respective auditory excerpts.

Very unpleasant

Very pleasant

Very relaxing

Very stimulating 
Figure 4. Correlation between the global IQ scores and the average number of words recalled.

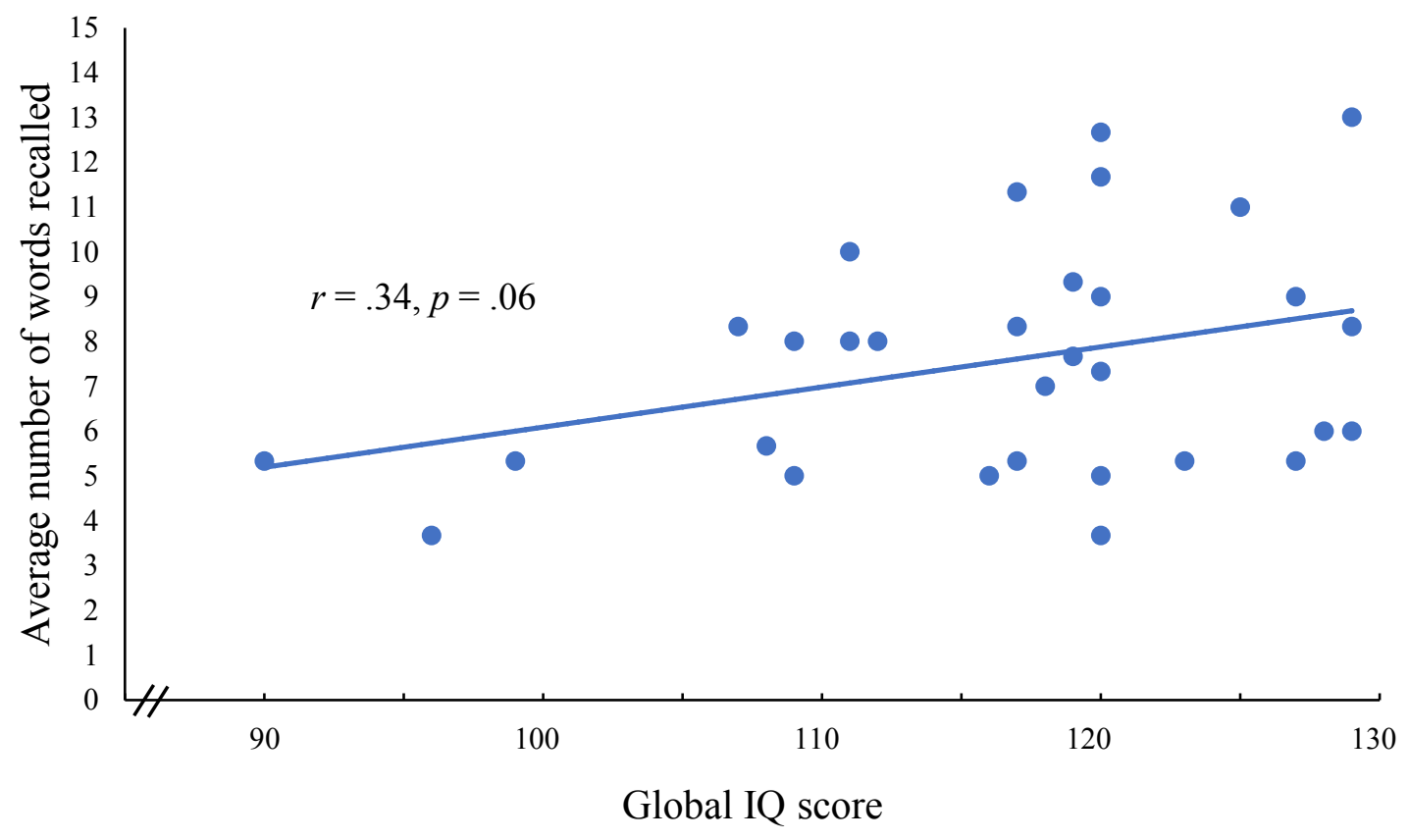


Figure 5. Average number of words recalled per list as a function of groups. The error bars represent standard deviations.

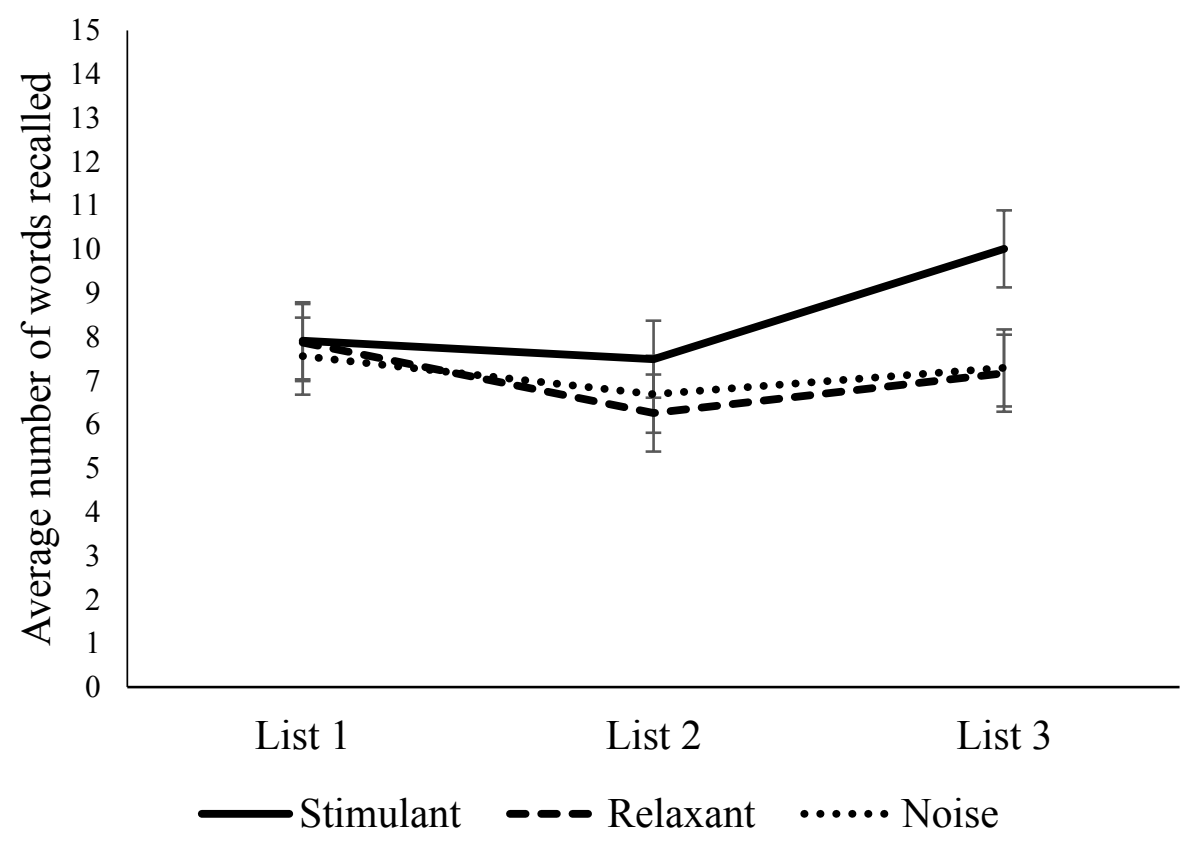

xxix 


\section{Appendix A : Word lists}




\begin{tabular}{|c|c|c|}
\hline List 1 & List 2 & List 3 \\
\hline Garage & Fromage & Balance \\
\hline Pomme & Lapin & Diamant \\
\hline Armoire & Sifflet & Gazon \\
\hline Lunette & Brosse & Fenêtre \\
\hline Cahier & Statue & Castor \\
\hline Charrue & Lampe & Pelle \\
\hline Coffre & Drapeau & Tuyau \\
\hline Journal & Chemise & Berceau \\
\hline Botte & Échelle & Camion \\
\hline Marteau & Tracteur & Barbe \\
\hline Talon & Branche & Miroir \\
\hline Valise & Oreille & Panier \\
\hline Tigre & Nappe & Orteil \\
\hline Filet & Radis & Chaise \\
\hline Brique & Corde & Feuille \\
\hline
\end{tabular}




\section{Appendix B : Mathematical equations}




\section{Operations (A)}

Calculate each sum, difference, product, or quotient.

\begin{tabular}{|c|c|c|c|}
\hline $9 \times 1=$ & $13-7=$ & $9-1=$ & $7+1=$ \\
\hline $11-5=$ & $18 \div 6=$ & $50 \div 10=$ & $11-9=$ \\
\hline $48 \div 8=$ & $5 \times 8=$ & $30 \div 10=$ & $3 \times 1=$ \\
\hline $30 \div 5=$ & $4 \div 4=$ & $9 \times 2=$ & $16 \div 4=$ \\
\hline $5 \times 10=$ & $4 \div 1=$ & $7-3=$ & $7-1=$ \\
\hline $10-3=$ & $18-10=$ & $9 \times 9=$ & $1 \times 3=$ \\
\hline $2 \div 2=$ & $6+9=$ & $17-8=$ & $4 \times 5=$ \\
\hline $6+1=$ & $2+7=$ & $2-1=$ & $5 \times 4=$ \\
\hline $12-7=$ & $7-3=$ & $8+2=$ & $10-7=$ \\
\hline $10+4=$ & $8 \times 1=$ & $45 \div 5=$ & $7 \times 5=$ \\
\hline $12-7=$ & $3-2=$ & $12-9=$ & $14-9=$ \\
\hline $18-10=$ & $3 \times 6=$ & $3 \times 7=$ & $16-8=$ \\
\hline $9+9=$ & $14-5=$ & $10 \times 8=$ & $4+1=$ \\
\hline $7 \times 4=$ & $15-10=$ & $4 \times 6=$ & $2+10=$ \\
\hline $1 \times 5=$ & $10-9=$ & $21 \div 3=$ & $20 \div 2=$ \\
\hline $5+7=$ & $13-5=$ & $2+6=$ & $10 \times 4=$ \\
\hline $9+8=$ & $4+3=$ & $10-4=$ & $48 \div 6=$ \\
\hline $2 \div 1=$ & $18 \div 2=$ & $7 \div 7=$ & $10 \times 5=$ \\
\hline $5-4=$ & $9-3=$ & $6-3=$ & $10+4=$ \\
\hline $6 \times 3=$ & $1+10=$ & $1+4=$ & $14-8=$ \\
\hline $8 \times 4=$ & $1 \times 2=$ & $9-7=$ & $1+5=$ \\
\hline $20 \div 2=$ & $3+10=$ & $4+7=$ & $15-10=$ \\
\hline $7-6=$ & $3+9=$ & $5 \times 8=$ & $17-8=$ \\
\hline $2+3=$ & $15-7=$ & $45 \div 9=$ & $7-3=$ \\
\hline $6+3=$ & $7+6=$ & $10+8=$ & $1 \times 4=$ \\
\hline
\end{tabular}


All Operations (B)

Calculate each sum, difference, product, or quotient.

\begin{tabular}{|c|c|c|c|}
\hline $8+7=$ & $16 \div 4=$ & $9 \times 3=$ & $12-6=$ \\
\hline $7-1=$ & $5 \times 4=$ & $14-4=$ & $3 \div 3=$ \\
\hline $6 \div 1=$ & $5 \times 9=$ & $8-3=$ & $7 \times 5=$ \\
\hline $18-8=$ & $20-10=$ & $1+5=$ & $2+1=$ \\
\hline $5+2=$ & $1 \div 1=$ & $30 \div 3=$ & $80 \div 8=$ \\
\hline $8-1=$ & $7+8=$ & $5+6=$ & $6 \div 6=$ \\
\hline $10+4=$ & $45 \div 5=$ & $7-1=$ & $9 \times 8=$ \\
\hline $8 \times 5=$ & $72 \div 8=$ & $19-10=$ & $9 \times 5=$ \\
\hline $9-5=$ & $8+5=$ & $2 \div 2=$ & $14-9=$ \\
\hline $14 \div 7=$ & $10+10=$ & $4+1=$ & $10+4=$ \\
\hline $100 \div 10=$ & $8+8=$ & $30 \div 10=$ & $90 \div 9=$ \\
\hline $2+1=$ & $1+9=$ & $8 \times 1=$ & $9+6=$ \\
\hline $4+5=$ & $2 \times 10=$ & $9 \times 2=$ & $10 \times 10=$ \\
\hline $3-2=$ & $10 \times 8=$ & $9+4=$ & $2-1=$ \\
\hline $4+9=$ & $7 \times 2=$ & $12 \div 3=$ & $1+8=$ \\
\hline $9-4=$ & $10+8=$ & $6+1=$ & $16-7=$ \\
\hline $25 \div 5=$ & $4 \times 7=$ & $8+1=$ & $2 \div 1=$ \\
\hline $12 \div 6=$ & $14-10=$ & $15 \div 5=$ & $4+3=$ \\
\hline $9 \times 8=$ & $12-2=$ & $7+2=$ & $10 \times 1=$ \\
\hline $1 \times 4=$ & $3+9=$ & $5 \times 3=$ & $2 \times 6=$ \\
\hline $2 \times 6=$ & $3+3=$ & $1 \times 5=$ & $10 \times 10=$ \\
\hline $4 \div 4=$ & $3 \times 2=$ & $6+4=$ & $10+9=$ \\
\hline $10-7=$ & $10+5=$ & $30 \div 5=$ & $5+6=$ \\
\hline $9 \times 2=$ & $1 \times 1=$ & $2+6=$ & $7+8=$ \\
\hline $1+7=$ & $12-6=$ & $9-6=$ & $2 \div 1=$ \\
\hline
\end{tabular}


Operations (C)

Calculate each sum, difference, product, or quotient.

\begin{tabular}{|c|c|c|c|}
\hline $10-6=$ & $1 \times 7=$ & $12-4=$ & $2 \times 9=$ \\
\hline $7 \div 1=$ & $5+8=$ & $9-2=$ & $6+2=$ \\
\hline $9 \times 6=$ & $7+7=$ & $10 \times 4=$ & $15-9=$ \\
\hline $18-10=$ & $8+10=$ & $6+2=$ & $3 \times 7=$ \\
\hline $8+8=$ & $13-8=$ & $30 \div 10=$ & $13-3=$ \\
\hline $7+5=$ & $27 \div 9=$ & $5 \times 9=$ & $12 \div 4=$ \\
\hline $6+3=$ & $4 \times 7=$ & $2+2=$ & $40 \div 4=$ \\
\hline $2 \times 10=$ & $10 \times 9=$ & $5 \times 10=$ & $5+8=$ \\
\hline $7 \times 3=$ & $16 \div 2=$ & $4 \times 4=$ & $5+8=$ \\
\hline $9+1=$ & $8 \div 2=$ & $4 \times 2=$ & $9+10=$ \\
\hline $1 \times 2=$ & $6 \div 6=$ & $63 \div 9=$ & $4+10=$ \\
\hline $2+1=$ & $30 \div 6=$ & $6 \times 5=$ & $6+10=$ \\
\hline $4+4=$ & $8-6=$ & $12-2=$ & $80 \div 10=$ \\
\hline $16 \div 4=$ & $10-9=$ & $8 \times 10=$ & $1 \times 10=$ \\
\hline $7+5=$ & $6 \times 6=$ & $45 \div 9=$ & $9 \div 9=$ \\
\hline $1 \times 3=$ & $13-8=$ & $11-10=$ & $11-4=$ \\
\hline $3+5=$ & $11-5=$ & $90 \div 10=$ & $4 \times 5=$ \\
\hline $3 \times 8=$ & $5-2=$ & $12-9=$ & $5 \div 1=$ \\
\hline $9+6=$ & $5-1=$ & $5+4=$ & $12-10=$ \\
\hline $9-3=$ & $14-8=$ & $9 \times 3=$ & $18 \div 9=$ \\
\hline $16 \div 2=$ & $8+1=$ & $70 \div 7=$ & $6 \times 3=$ \\
\hline $11-2=$ & $11-9=$ & $6-5=$ & $14-7=$ \\
\hline $8-4=$ & $1+5=$ & $9 \times 3=$ & $5 \times 1=$ \\
\hline $48 \div 6=$ & $6+9=$ & $3 \times 5=$ & $4 \div 2=$ \\
\hline $5 \times 9=$ & $5 \times 5=$ & $5 \times 8=$ & $8 \times 10=$ \\
\hline
\end{tabular}

